Sains Malaysiana 48(2)(2019): 451-471

http://dx.doi.org/10.17576/jsm-2019-4802-24

\title{
Mixed Convection in Lid-Driven Cavity with Inclined Magnetic Field
}

(Perolakan Campuran dalam Rongga Berpenutup Bergerak dengan Medan Magnet Condong)

\author{
N.A. BAKAR, R. ROSLAN, A. KARIMIPOUR \& I. HASHIM*
}

\section{ABSTRACT}

Effects of magnetic field inclination on fluid flow and heat transfer in a two-dimensional square cavity are analyzed numerically. The vertical walls are well insulated, the bottom wall is maintained at a cold temperature, while the top moving lid is kept at a hot temperature. The finite volume method and SIMPLE algorithm are employed to solve the dimensionless governing equations. The results are presented by the profile of streamlines and isotherms, and the variation of Nusselt number. Mixed convection flow is retarded by the presence of the magnetic field and the average Nusselt number is an increasing function of the magnetic field angle.

Keywords: Finite volume method; inclined magnetic field; lid-driven; mixed convection

\section{ABSTRAK}

Kesan kecondongan medan magnet pada aliran bendalir dan pemindahan haba dalam rongga empat segi dua dimensi dianalisis secara berangka. Dinding menegak berpenebat dengan baik, dinding bawah dikekalkan pada suhu sejuk, manakala penutup atas yang bergerak dikekalkan pada suhu panas. Kaedah isi padu terhingga dan algoritma SIMPLE digunakan untuk menyelesaikan persamaan menakluk tanpa dimensi. Keputusan dibentangkan dalam bentuk profil aliran dan isoterma dan variasi nombor Nusselt. Kadar aliran perolakan campuran diperlahankan dengan kehadiran medan magnet dan purata nombor Nusselt adalah fungsi menokok terhadap sudut medan magnet.

Kata kunci: Kaedah isi padu terhingga; medan magnet condong; penutup bergerak; perolakan campuran

\section{INTRODUCTION}

Atmospheric flow, heat exchangers, drying technologies, lubricant technologies, and cooling of the electronic devices are examples of phenomena involving mixed convection flow in a cavity, where both natural and forced convection take place at the same time. Due to the shear flow caused by the movement of the moving wall and the buoyancy-induced flow, the study of flow in lid-driven cavities is complex and has attracted the attention of many researchers. One of the earliest investigations on mixed convection in lid-driven cavity was conducted by Torrance et al. (1972). They reported that an increase in the aspect ratio led to an increase in secondary circulation in the cavity. Later, Moallemi and Jang (1992) studied the effect of the Prandtl number Pr on the laminar mixed convection heat transfer in a lid-driven cavity numerically. The numerical results showed that for higher values of Pr, the effect of thermal buoyancy force on the flow and heat transfer inside the cavity is more pronounced. Then, Iwatsu et al. (1993) investigated numerically mixed convection heat transfer in a driven cavity with a stable vertical temperature gradient. It was reported that for high values of the Richardson number, much of the fluid in both the middle and bottom portions of the cavity interior is stagnant. Khanafer and Chamkha (1999) studied mixed convection flow in a lid-driven enclosure filled with a fluidsaturated porous medium numerically. It was found that the
Darcy and Richardson numbers are important parameters in convective flows. Later on, Biswas et al. (2016) studied the importance of using adiabatic block inside a lid-driven cavity to enhance thermal energy transport. The results showed that the presence of an adiabatic block possibly suppresses the energy circulation. Then, Biswas and Manna (2017a) investigated the free aspiration of surrounding fluid that could possibly affect the heat transfer in a cavity. The study concluded that aspiration can enhance the heat transfer without any extra expenses. In addition, Biswas and Manna (2017b) presented the energy transport system when a cavity is heated from the bottom wall with different combination of wall motion and thermal condition are applied.

Magnetic field is an external force on thermal and energy systems that highly affect the heat transfer and flow field. Rudraiah et al. (1995) studied the effects of magnetic field on free convection in a rectangular cavity. They found that convection was suppressed and the rate of heat transfer decreased when the magnetic strength is increased. Earlier, Garandet et al.(1992) analyzed the effect of magnetic field on free convection flow in a rectangular enclosure. Then, two-dimensional unsteady simulation of MHD natural convection in a laterally and volumetrically heated square enclosure filled with liquid-metal was examined by Sarris et al. (2005). Different thermal boundary conditions with the existence of magnetic field on natural convection are 
discussed by Oztop et al. (2009) and Pirmohammadi et al. (2009). Ishak (2011) studied the effect of radiation on magnetohydrodynamic (MHD) boundary layer flow of a viscous fluid over an exponentially stretching sheet. It was found that the local heat transfer rate at the surface decreases with increasing values of the magnetic and radiation parameters. The problem of laminar viscous flow in a semi-porous channel in the presence of transverse magnetic field is studied by Shekholeslami et al. (2012). The Optimal Homotopy Asymptotic Method (OHAM) is employed to approximate the solution of the system and were compared with homotopy analysis method (HAM) and variation iteration method (VIM) results. They showed that shows that OHAM is a powerful approach for solving nonlinear differential equations.

Various investigations on mixed convection heat transfer in a lid-driven cavity in the presence of magnetic field are conducted. For instance, Chamkha (2002) studied the effects of magnetic field and internal heat generation or absorption to the opposing and aiding flow. It was found that the presence of magnetic field strongly affected the heat transfer and flow behaviors. Then, Rahman et al. (2010) reported on the conjugate effect of joule heating and magnetic field in an obstructed lid-driven cavity to the flow and heat transfer characteristics. It is found that the obstacle strongly affected the thermal field at forced convection regime and the flow field at mixed convection regime. Malleswaran et al. (2013) and Oztop et al. (2011) studied the effects of different heating locations in the presence of magnetic field in a lid-driven cavity to the flow and heat transfer rate. They reported that heating location and existence of magnetic field have a significant role in the heat transfer rate and fluid flow behavior. Hydromagnetic effects on mixed convection in a lid-driven cavity are studied by Nasrin and Parvin (2011) and Sivasankaran et al. (2011). Sivasankaran et al. (2011) investigated the effects of sinusoidal temperature on both sidewalls, while Nasrin and Parvin (2011) investigated them with sinusoidal corrugated bottom surface cavity. Both studies reported that the magnetic field plays important role in the convection heat transfer rate and fluid flow behaviors. Al-Salem et al. (2012) and Kefayati et al. (2012) studied magnetohydrodynamic mixed convection in a lid-driven cavity having a linearly heated wall. Then, Biswas and Manna (2017c) explored the impact of magnetic fields in association with the triple convection taking place simultaneously in the presence of external magnetic field. The circulation from Marangoni convection is greatly affected by magnetic fields.

The physical involvement of fluid flow problem due to an inclined magnetic field is found through the application of it. The study of the design of MHD power generator, MHD pumps and accelerators are some of the applications. One of the most important application that used inclined magnetic field is magnetic resonance imaging (MRI) in the medical industry. Koopaee and Jelodari (2014) investigated magnetic field inclination angle on transient natural convection in an enclosure filled with nanofluid.
They found that heat transfer increases as the inclination angle increases and decreases as the solid volume fraction increases. Later, Mansour et al. (2010) analyzed the effect of an inclined magnetic field on the natural convection in an inclined cavity filled with fluid saturated porous medium. Meanwhile, Mondal and Sibanda (2015) considered the unsteady double diffusive natural convection in an inclined rectangular cavity with different magnetic field angles and non-uniform boundary conditions. Ahmed et al. (2013) extended the work of Sivasankaran et al. (2011) and studied the effects of both magnetic field and cavity inclination angle on the mixed convection heat transfer and flow behaviors. The results showed that heat transfer rate is enhanced by increasing either the Hartmann number or cavity inclination angle. Very recently, Naganthran et al. (2018) studied the effect of thermal radiation on mixed convection flow over a permeable vertical shrinking flat plate.

Udhayakumar et al. (2016) investigated the effects of magnetohydrodynamic mixed convection over an isothermal circular cylinder in presence of an aligned magnetic field. Meanwhile, Hussain et al. (2016) studied on mixed convection in a double lid-driven cavity filled with nanofluid and the cavity is imposed to entropy generation along with discrete heating. In addition, Hussain et al. (2017) reinforced the study with inclined cavity filled with different nanofluid. They concluded that the inclination angle caused the increment on the average Nusselt number due to the left heated wall. Then, Mehmood et al. (2017) studied the effect of non-linear thermal radiation and inclined magnetic field in a nanofluid filled cavity. They reported that all the parameters in selected ranges declined heat transfer due to the hot bottom wall. Gibanov et al. (2017a) investigated the effect of inclined magnetic field in a lid-driven cavity filled with nanofluid and porous medium. Then, Gibanov et al. (2017b) extended their study by examined the effect of mixed convection in a lid-driven cavity with the presence of heat-conducting solid clock and imposed to variable magnetic field.

Recently, Mondal and Sibanda (2018) conducted the study on an unsteady double-diffusive natural convection flow in an inclined rectangular enclosure subject to an inclined magnetic field and heat generation parameter. They found that distinctive edges of the magnetic field stifle the convection flow and its direction affects the stream designs. The problem of mixed convection in a lid-driven trapezoidal cavity filled with nanofluid under the effect of an inclined magnetic field was numerically investigated for various electrical conductivity models by Selimefendigil and Oztop (2018). At the same time, Selimefendigil and Chamkha (2018) conducted a numerical simulation of mixed convection heat transfer in a lid-driven triangular cavity filled with nanofluid and with an opening under the effect of an inclined magnetic field. They found that the average Nusselt number depends on the fluid type and inclination angle of the magnetic field. Meanwhile, Hussain et al. (2018a) have performed a computational analysis on mixed convection in a double lid-driven cavity with the presence of 
volumetric heat generation and inclined magnetic field. Their finding showed that heat transfer decreased with increasing the magnetic field strength and nanoparticle volume. Next, Hussain et al. (2018b) reported on the impact of periodic magnetic field on entropy generation and mixed convection in a double lid-driven cavity that is filled with nanofluid. The results showed that the increase of magnetic field strength causes an increment in the average entropy generation due to the magnetic field.

From the literatures and keeping in view of the previously-mentioned industrial applications, it is observed that the study on the effect of inclined magnetic field is important to predict the heat transfer and flow field in a lid-driven cavity. Apart of the aforementioned studies, there is no work has been done on a lid-driven cavity filled with water having the magnetic field imposed to the cavity. Therefore, this study is focused on the effect of magnetic inclination angle on mixed convection heat transfer in a lid-driven cavity. Moreover, it becomes important to study on the impact of inclination angle of the magnetic field to reach deep insight of the fluid flow pattern. Here, the numerical results in terms of streamlines, isotherms and average Nusselt number are presented graphically and in tabular form.

\section{GOVERNING EQUATIONS}

The physical configuration is shown in Figure 1(a). The vertical side walls of the square cavity are thermally insulated. The top wall is moving rightwards at a constant velocity $U_{0}$ and sustained at the hot temperature, $T_{h}$. The bottom wall is kept at constant cold temperature $T_{c}$ where $T_{h}>T_{c}$. The height and length of the cavity are denoted by $L$. A uniform magnetic field of strength $B$ is percolated to the cavity in different inclination angle ranging from $0^{\circ}$ to $90^{\circ}$ in the counter-clockwise direction from the $x$-axis. The working fluid is considered Newtonian and incompressible. The flow in the enclosure is twodimensional, laminar and steady. The Boussinesq approximation is valid for the density variation in the buoyancy term and the other thermo-physical properties of the fluid are taken to be constant (Bejan 2013). Based on the assumptions mentioned above, the system of equations and boundary conditions can be written as follows,

$$
\begin{aligned}
\frac{\partial u}{\partial x}+\frac{\partial v}{\partial y}=0 & \\
u \frac{\partial u}{\partial x}+v \frac{\partial u}{\partial y}= & -\frac{1}{\rho} \frac{\partial p}{\partial x}+v\left(\frac{\partial^{2} u}{\partial x^{2}}+\frac{\partial^{2} u}{\partial y^{2}}\right) \\
& +\frac{B^{2} \sigma}{\rho}\left(v \sin \gamma \cos \gamma-u \sin ^{2} \gamma\right) \\
u \frac{\partial v}{\partial x}+v \frac{\partial v}{\partial y}= & -\frac{1}{\rho} \frac{\partial p}{\partial y}+v\left(\frac{\partial^{2} v}{\partial x^{2}}+\frac{\partial^{2} v}{\partial y^{2}}\right) \\
& +\frac{B^{2} \sigma}{\rho}\left(u \sin \gamma \cos \gamma-v \cos ^{2} \gamma\right)+g \beta\left(T-T_{c}\right)
\end{aligned}
$$

$$
u \frac{\partial T}{\partial x}+v \frac{\partial T}{\partial y}=\alpha\left(\frac{\partial^{2} T}{\partial x^{2}}+\frac{\partial^{2} T}{\partial y^{2}}\right) .
$$

The boundary conditions are:

top wall: $u=U_{0}, v=0, T=T_{h}$,

bottom wall: $u=v=0, T=T$,

left and right walls: $\mathrm{u}=\mathrm{v}=0, \frac{\partial T}{\partial x}=0$,

where $u$ and $v$ are the velocity components in the $x$ - and $y$-direction respectively; $v$ is the kinematic viscosity; $\rho$ is the density; $p$ is the pressure; $B$ is the magnetic induction; $\sigma$ is the electrical conductivity; $g$ is the gravity; $\beta$ is the coefficient of thermal expansion; $T$ is the temperature while $T_{c}$ and $T_{h}$ are cold temperature and hot temperature, respectively, such that $T_{h}>T_{c}, \gamma$ is the inclination angle of the magnetic field and $\alpha=k / \rho c$ is the thermal diffusivity where $k$ is the thermal conductivity; $c$ is the specific heat capacity; and $U_{0}$ is the constant velocity of top lid.

The dimensionless variables are define as follows:

$$
\begin{aligned}
& X=\frac{x}{L}, \quad L=\frac{y}{L}, \quad U=\frac{u}{U_{0}}, V=\frac{v}{U_{0}}, \theta=\frac{T-T_{c}}{T_{h}-T_{c}}, \\
& H a=B L \sqrt{\frac{\sigma}{\rho v}}, \quad G r=\frac{g \beta\left(T_{h}-T_{c}\right)}{v^{2}}, \quad \operatorname{Pr}=\frac{v}{\alpha}, \\
& P=\frac{p}{\rho U_{0}^{2}}, \quad \operatorname{Re}=\frac{U_{0} L}{v},
\end{aligned}
$$

then, the dimensionless governing equations are written as:

$$
\begin{aligned}
\frac{\partial U}{\partial X}+\frac{\partial V}{\partial Y}=0, & \\
U \frac{\partial U}{\partial X}+V \frac{\partial U}{\partial Y}= & -\frac{\partial P}{\partial X}+\frac{1}{R e}\left(\frac{\partial^{2} U}{\partial^{2} X}+\frac{\partial^{2} U}{\partial^{2} Y}\right) \\
& +\frac{H a^{2}}{R e}\left(V \sin \gamma \cos \gamma-U \sin ^{2} \gamma\right) .
\end{aligned}
$$

$$
\begin{aligned}
U \frac{\partial V}{\partial X}+V \frac{\partial V}{\partial Y}= & -\frac{\partial P}{\partial Y}+\frac{1}{R e}\left(\frac{\partial^{2} V}{\partial^{2} X}+\frac{\partial^{2} V}{\partial^{2} Y}\right) \\
& +\frac{H a^{2}}{R e}\left(U \sin \gamma \cos \gamma-V \cos ^{2} \gamma\right)+\frac{G r}{R e^{2}} \theta .
\end{aligned}
$$

$$
U \frac{\partial \theta}{\partial X}+V \frac{\partial \theta}{\partial Y}=\frac{1}{R e \operatorname{Pr}}\left(\frac{\partial^{2} \theta}{\partial^{2} X}+\frac{\partial^{2} \theta}{\partial^{2} Y}\right) .
$$

The dimensionless boundary conditions for the present problem are: 
top wall: $U=1, V=0, \theta=1$,

bottom wall: $U=V=0, \quad \theta=0$,

left and right walls: $U=V=0, \frac{\partial \theta}{\partial X}=0$.

Here, the dimensionless parameter in the stated governing equations are defined as follows, $G r$ is the Grashof number; Pr is the Prandtl number; and $R e$ is the Reynolds number. $P$ and $\theta$ are the dimensionless pressure and temperature, respectively. The stream function is computed from its definition as $U=\frac{\partial \psi}{\partial Y}$ and $V=-\frac{\partial \psi}{\partial X}$.

\section{NUMERICAL APPROACH}

The governing equations (6)-(9) with the boundary conditions given are solved numerically by utilizing the finite volume method in order to investigate the steady thermal behaviour in the square cavity with the presence of inclined magnetic field. In the present investigation, the non-uniform mesh system is implemented to capture the rapid changes of all the variables especially near the walls. In addition, a staggered grid system is adopted where the velocity components are stored halfway between the scalar storage locations. As given by Patankar (1980), the semi implicit method for pressure linked equation (SIMPLE) algorithm is used to couple the continuity and momentum equations. The power law scheme was applied for discretizing the diffusion and convection terms. Then, the fully discretized equations is solved iteratively using a line-by-line Tri-Diagonal Matrix Algorithm, TDMA procedure. FORTRAN90 programming code is used to solve the present problem. The program runs iteratively until the following convergence criterion is fulfilled,

$$
\varepsilon=\frac{\sum_{i, j}\left|\xi_{i, j}^{t+1}-\xi_{i, j}^{t}\right|}{\sum_{i, j}\left|\xi_{i, j}^{t+1}\right|} \leq 10^{-7}
$$

where $\varepsilon$ is the tolerance; $\xi$ is any of the computed field variables; and $t$ is the iteration number. The local and average rate of heat transfer are described by the local Nusselt number along the hot wall and the average Nusselt number that are written as $N u_{x}=-\left(\frac{\partial \theta}{\partial Y}\right)_{Y=1}$, and $\overline{N u}=\int_{0}^{1} N u_{x} d X$ respectively. The non-uniform grid with finer mesh near the cavity walls and staggered grid system is selected in both $X$ and $Y$-directions in order to obtain accurate results. Figure 1(b) shows the grid system used in this study. However, the creation for this technique is not included in this paper as it is not the focus of this study.

A grid sensitivity analysis is performed to achieve optimal adjustment between the numerical accuracy and the computational cost of solution procedure. Various grid size from $61 \times 61$ to $121 \times 121$ and the resulting average Nusselt number along the heated top wall for $\operatorname{Pr}=7.0, R i$ $=1.0, \operatorname{Re} 100.0, \mathrm{Ha}=30.0$, and $\gamma=30^{\circ}$ is presented in

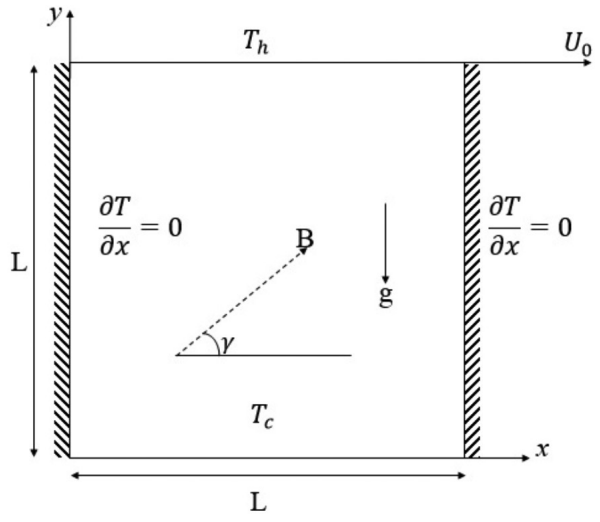

FIGURE 1. a) The physical model configuration

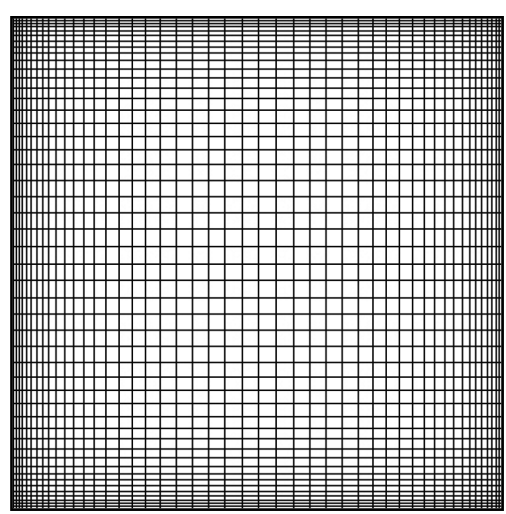

FIGURE 1. b) Non-uniform grid system

Table 1 . A grid with $101 \times 101$ size and $0.324 \%$ of error is sufficiently fine to ensure a grid-independent solution.

The present code using the FORTRAN90 programming language is validated against published works in the literature on convective flow in lid-driven cavities of Iwatsu et al. (1993) and Khanafer and Chamkha (1999). Table 2 shows that excellent agreement between present numerical simulation and those in the literature. Furthermore, the present code is validated against published work of AlSalem et al. (2012). Figure 2 shows the streamlines and isotherms for $R e=100.0, G r=10^{5}$ and $H a=30.0$. From Figure 2 it is clear that the plots between the two numerical results are in good agreement.

\section{RESULTS AND DISCUSSION}

In this paper, the problem of mixed convection flow of fluid in a square cavity with the presence of inclined magnetic field has been investigated numerically. Water is chosen as the working fluid throughout this study with Prandtl number, $\operatorname{Pr}=7.0$. The Reynold number is fixed at $R e=100.0$ and the Grashof number is varied in the range from $10^{3}$ to $10^{5}$. The Richardson number, $R i=\frac{G r}{R e^{2}}$, the magnetic field parameter, $H a$, and the magnetic field inclination angle, $\gamma$ are the controlling parameters on the fluid flow. $R i$ is ranging from 0.1 to $10.0, H a$ is taken as $0,10,30$, or 60 , 
TABLE 1. The average Nusselt number and the number of grids for $\operatorname{Pr}=7.0$, $R i=1.0, R e=100.0, H a=30.0$ and $\gamma=30^{\circ}$

\begin{tabular}{ccc}
\hline Grid & Average Nusselt number, $\overline{\mathrm{Nu}}$ & $\%$ error \\
\hline $61 \times 61$ & 1.847 & - \\
$81 \times 81$ & 1.852 & 0.27071 \\
$101 \times 101$ & 1.858 & 0.3240 \\
$121 \times 121$ & 1.864 & 0.3229 \\
\hline
\end{tabular}

TABLE 2. Comparisons of the maximum and minimum values of the horizontal and vertical velocities at the mid-section of the cavity between present solution and the works by Iwatsu et al. (1993) and Khanafer and Chamkha (1999)

\begin{tabular}{lccc}
\hline & \multicolumn{2}{c}{$R e=400.0$} \\
\cline { 2 - 4 } & Iwatsu et al. (1993) & Khanafer and Chamkha (1999) & Present \\
\hline$U_{\min }$ & -0.3197 & -0.3099 & -0.3023 \\
$U_{\max }$ & 1.0000 & 1.0000 & 1.0000 \\
$V_{\min }$ & -0.4459 & -0.4363 & -0.4219 \\
$V_{\max }$ & 0.2955 & 0.2866 & 0.2802 \\
\hline & & $R e=100.0$ & \\
\hline$U_{\min }$ & -0.2122 & -0.2037 & -0.2049 \\
$U_{\max }$ & 1.0000 & 1.0000 & 1.0000 \\
$V_{\min }$ & -0.2506 & -0.2448 & -0.2328 \\
$V_{\max }$ & 0.1765 & 0.1699 & 0.1673 \\
\hline
\end{tabular}

Streamlines
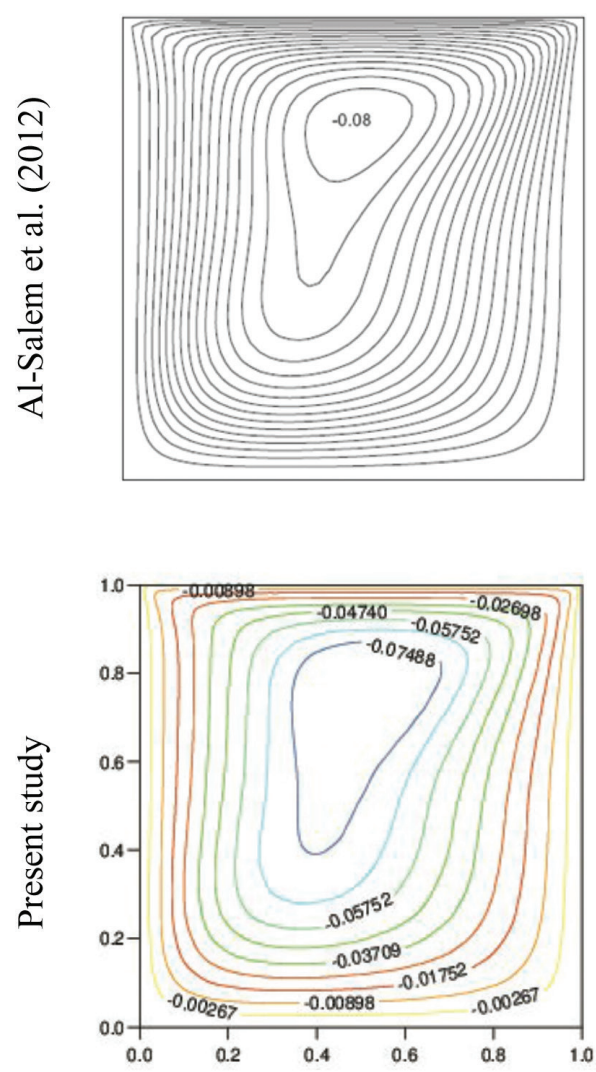

Isotherms
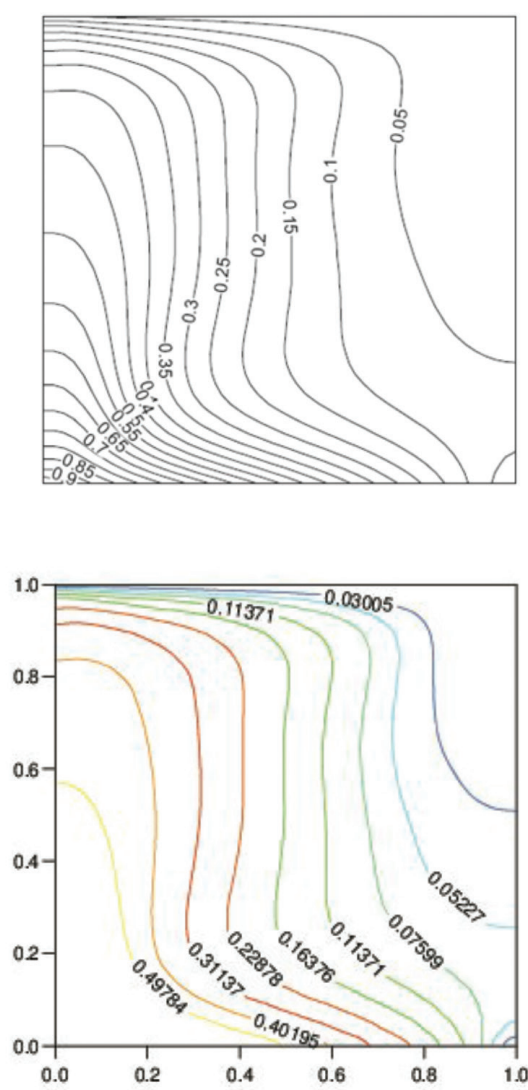

FIGURE 2. Comparison of present results with Al-Salem et al. (2012) 
while $\gamma$ is ranging from $0^{\circ}$ to $90^{\circ}$ by tilting the magnetic field counter-clockwise. The results are presented at three different regime: forced convection $(R i=0.1)$, mixed convection $(R i=1.0)$ and natural convection $(R i=10.0)$ in streamlines and isotherms plot.

The variation of streamlines and isotherms in the cavity for $R i=0.1, R e=100.0, G r=10^{3}$, with various values of $H a$ and $\gamma$ are presented in Figures 3 - 6. Figure 3 depicts the effect of different strength of $\mathrm{Ha}$ applied in the parallel direction to the $x$-axis. The streamlines show that a clockwise recirculating vortex occupied major upper part of the cavity. In the lower part of the cavity, there exist a secondary recirculating vortex in counterclockwise direction. This is due to the forced convection influence where the shear effect exerted by the top wall has overcome the buoyancy effect. Adding up the strength of $\mathrm{Ha}$ to 30 , the secondary vortex has developed into a bigger recirculating vortex. A tiny recirculating vortex is detected in the bottom right corner of the cavity. As the strength of magnetic field increases to $H a=60.0$, the third recirculating vortex is getting bigger and circulating in clockwise direction. This means that the magnetic field has slowed down the movement of the fluid in the cavity. The increment of magnetic field strength has inhibited the flow circulation gradually. The isotherms illustrate a steep temperature gradient in the middle and upper left corner of the cavity. This is due to shear force of the top lid that dominated the flow. The isotherms
Streamlines
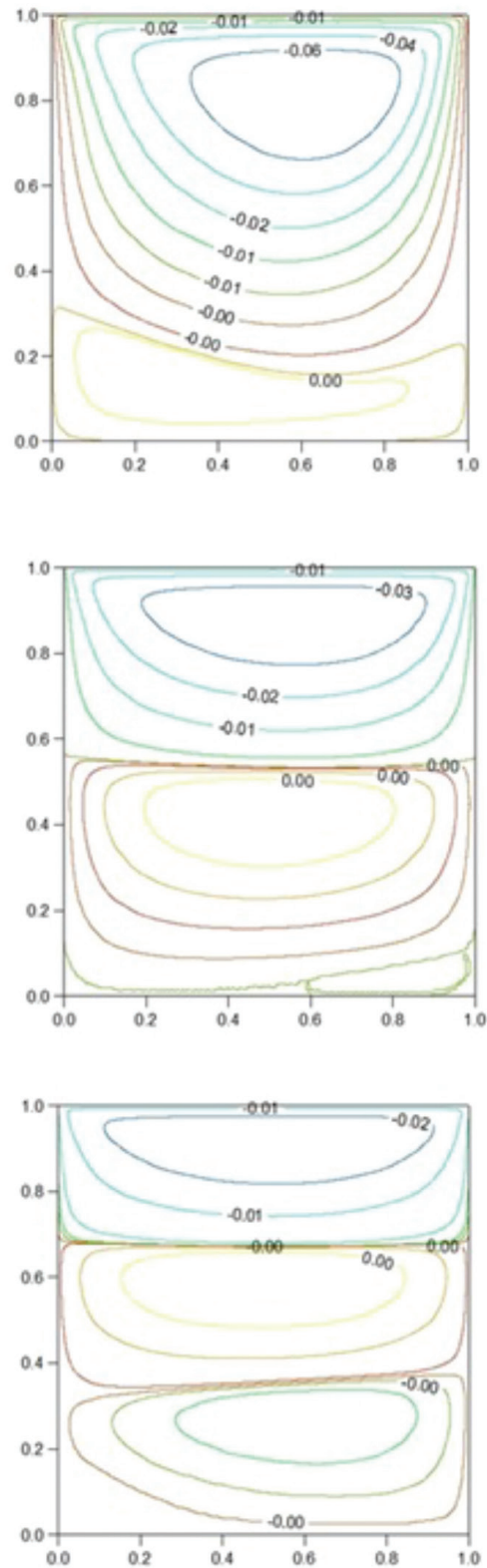

$H a=10.0$

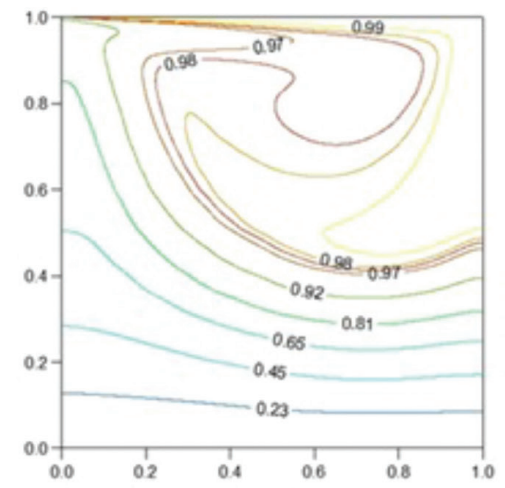

$H a=30.0$
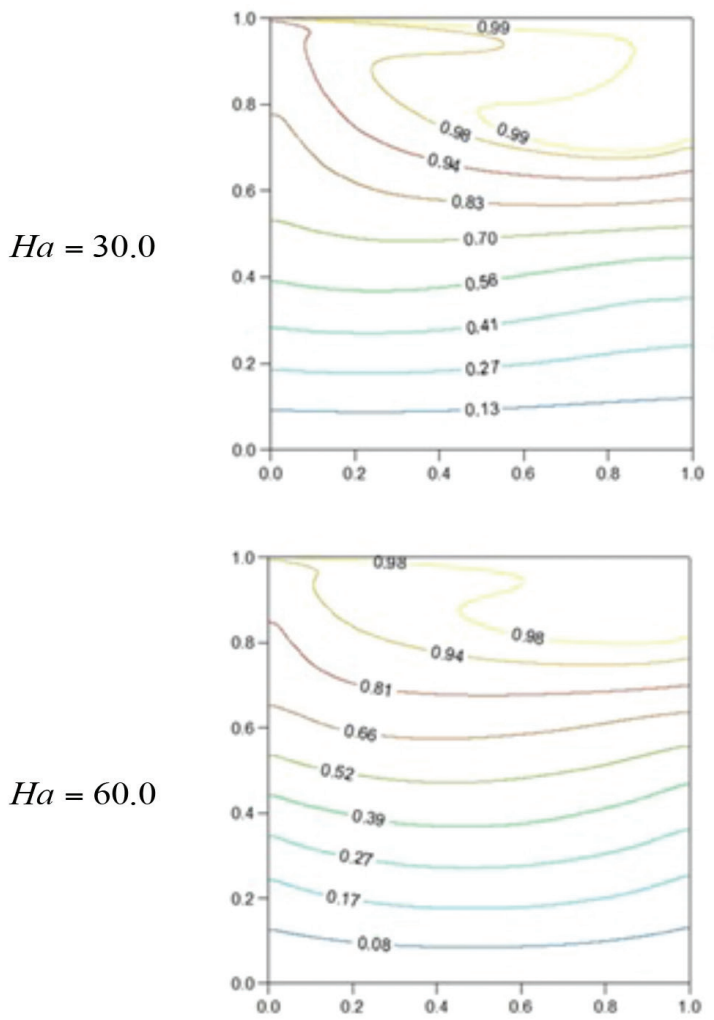

FIGURE 3. Variation of streamlines and isotherms in the cavity with $R i=0.1, R e=100.0$, $G r=10^{3}, \gamma=0^{\circ}$ and different Hartmann number 
show that along the bottom cavity, the fluid is thermally stratified. As increasing the strength of magnetic field, the fluid is horizontally stratified in most of the cavity starting along the bottom wall towards the upper part. The steep temperature gradient diminished gradually as the magnetic field increase. This implies that the heat is transferred by conduction.

The variation of streamline and isotherms in the cavity for the increase of magnetic field inclination angle to $30^{\circ}$ is shown in Figure 4 . The streamline contour shows that for $\gamma=30^{\circ}$ and $H a=10.0$, the cavity is filled with a primary recirculating vortex in counter-clockwise direction. Increasing the magnetic field $H a=30.0$, the streamlines stoop a little to the bottom left corner. When the strength of magnetic field is added to 60, the streamlines stoop in the same direction and it seem that the flow is compress to the moving wall. It is noticed that imposing the inclined magnetic field to the flow has weaken and skewed the streamline circulation to the left bottom wall. The temperature contours shows that when $H a=10.0$, steep temperature gradient is found at the top left corner and at the right wall in the middle of the cavity. This mean that convection dominant regime at the mentioned part of the cavity. As the magnetic field increases, the steep temperature gradient diminished. The circulation near the top region of the cavity decrease as well. It can be seen that the fluid is thermally stratified at the bottom region up to the middle of the cavity when $H a=30.0$. When $H a=$
Streamlines
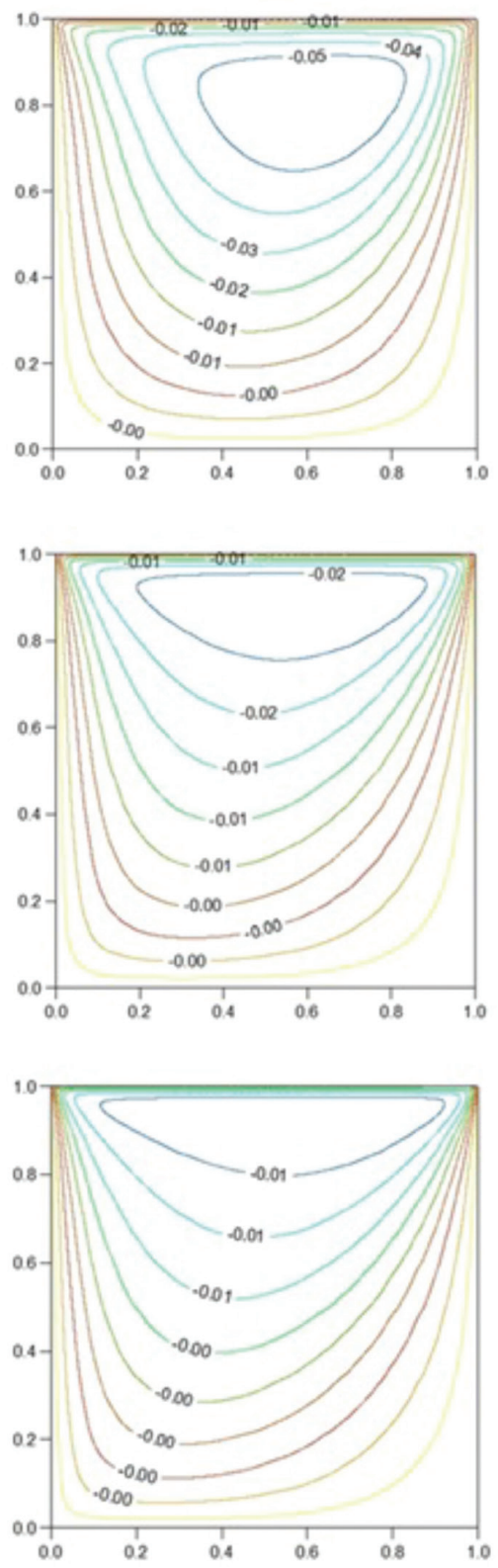

$H a=10.0$

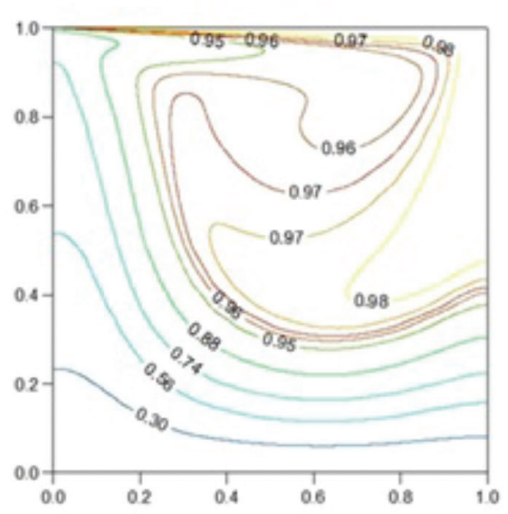

$H a=30.0$

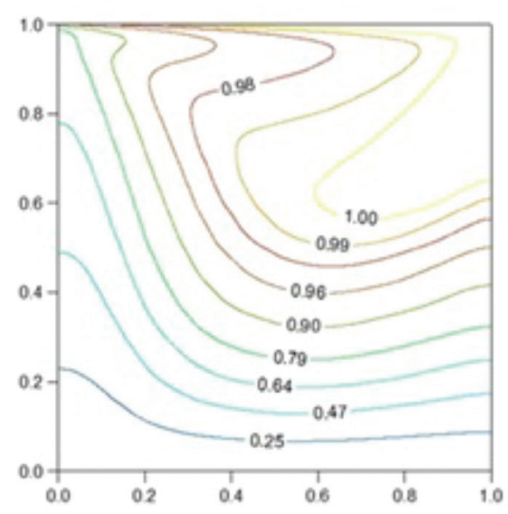

$H a=60.0$

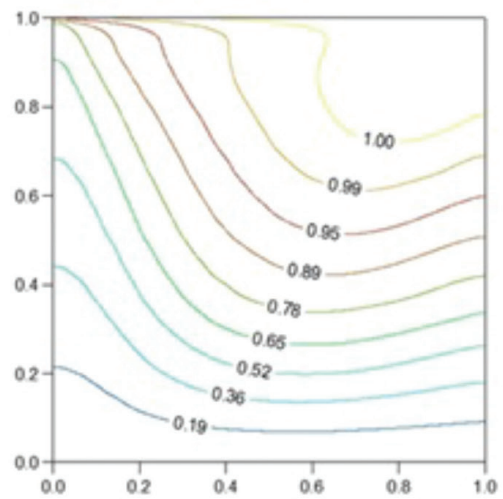

FIGURE 4. Variation of streamlines and isotherms in the cavity with $R i=0.1, R e=100.0$, $G r=10^{3}, \gamma=30^{\circ}$ and different Hartmann number 
60.0 , the fluid is stratified at most of the cavity indicating conduction dominated regime.

Figure 5 presents the variations of streamlines and isotherms with $R i=0.1, R e=100.0$, and $G r=10^{3}$ and $\gamma=$ $60^{\circ}$ with different $\mathrm{Ha}$. It is observed that the streamlines and isotherms contour are quite the same as when $\gamma=$ $30^{\circ}$. However, the isotherms contour are almost vertically stratified as the magnetic field increase. When $\gamma=90^{\circ}$, the variations of streamlines and isotherms are shown in Figure 6. It is observed that the fluid flow is represented by a primary counter-clockwise recirculating vortex for all values of $\mathrm{Ha}$. Moreover, the streamlines are compressed to the moving wall as the magnetic strength is increased. The isotherms show that the fluid is almost vertically stratified near the left wall as the magnetic strength increases.

Streamlines and isotherms for $R i=1.0, R e=100.0$, $G r=10^{4}$, with various values of $H a$ and $\gamma$ are presented in Figures $7-10$. For $\gamma=0^{\circ}$, the effect of various $\mathrm{Ha}$ can be observed from Figure 7. The streamlines show that as the $H a$ increases, a new vortex developed near the bottom wall in an alternate recirculating manner

\section{Streamlines}
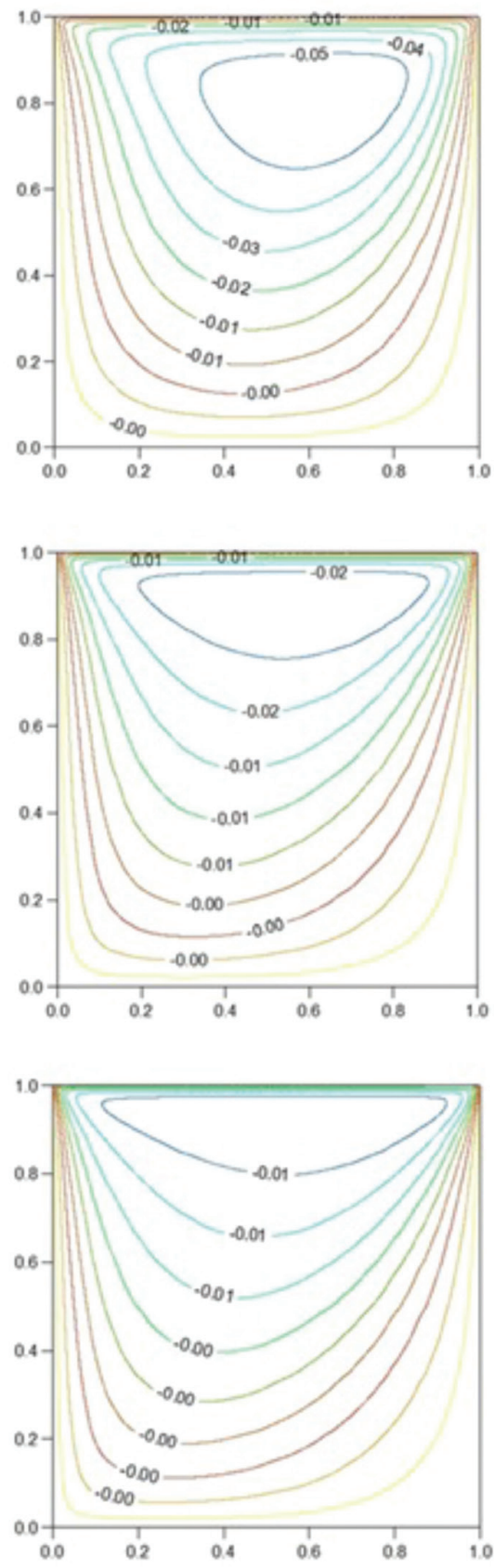

Isotherms

$H a=10.0$

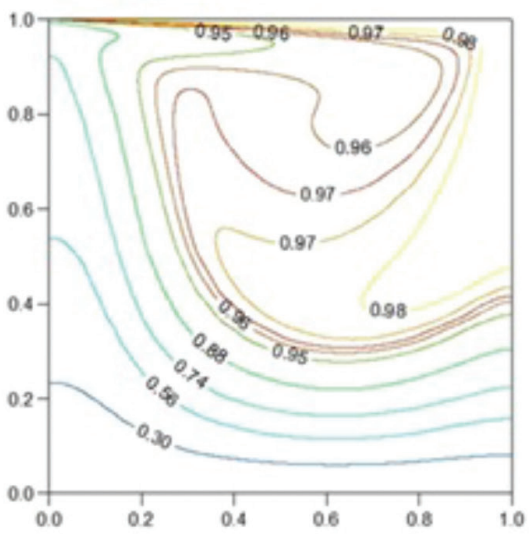

$H a=30.0$
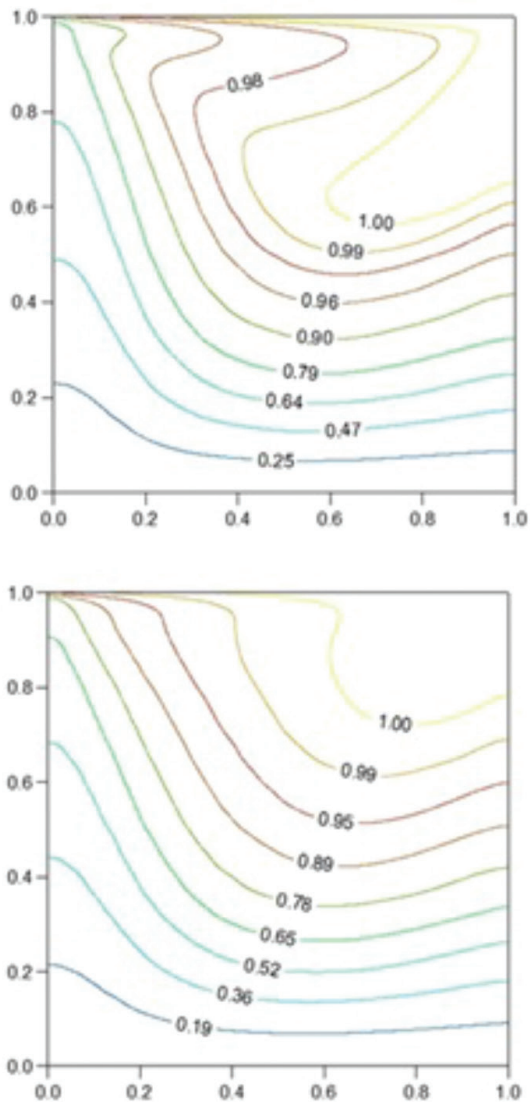

FIGURE 5. Variation of streamlines and isotherms in the cavity with $R i=0.1, R e=100.0$, $G r=10^{3}, \gamma=60^{\circ}$ and different Hartmann number 


\section{Streamlines}
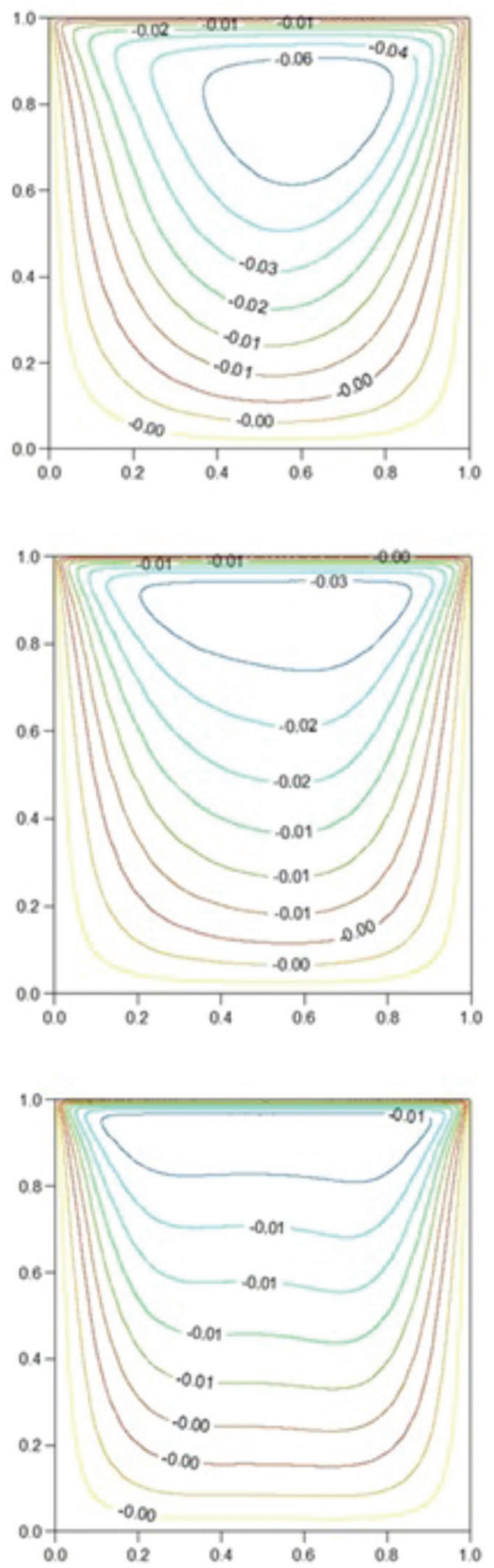

\section{Isotherms}

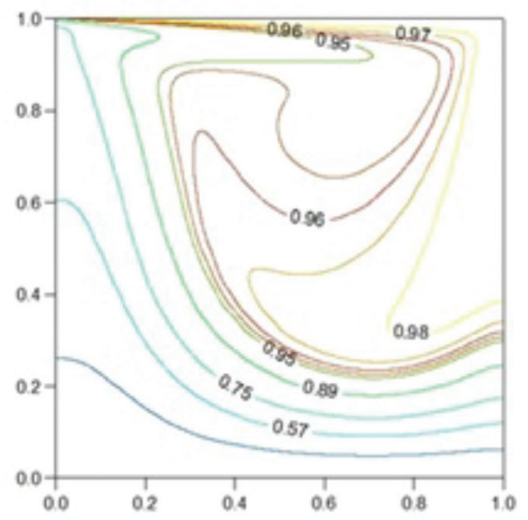

$H a=30.0$

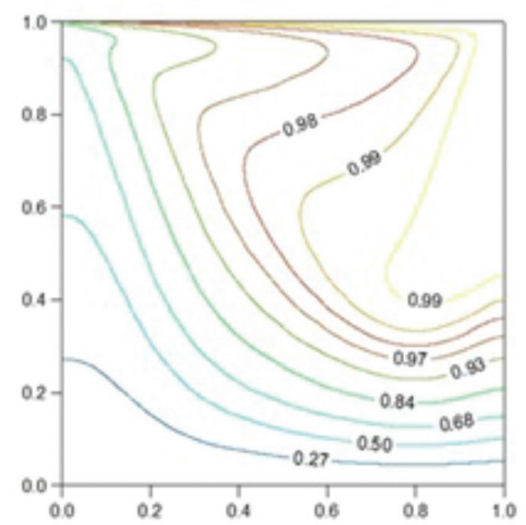

$H a=60.0$

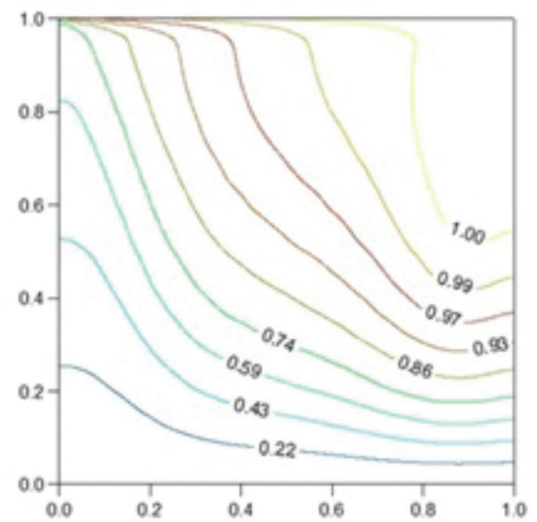

FIGURE 6. Variation of streamlines and isotherms in the cavity with $R i=0.1, R e=100.0$ $G r=10^{3}, \gamma=90^{\circ}$ and different Hartmann number

from the top vortex. This showed that the convection effect is decreasing as the strength of the magnetic field is increased. The fluid flow is retarded by the increase of magnetic field. In line with that, the isotherms show a quasi-conduction domain, that is, the heat is transferred by conduction except at the region near the sliding lid as the strength of magnetic field is increased. The same pattern of streamlines and isotherms as when $\gamma=0^{\circ}$ can be seen from Figure 8 for $R i=1.0, R e=100.0, G r=10^{4}$ with $\gamma=$ $30^{\circ}$. However, as the magnetic field increases, the second vortex near the bottom wall is diminished; leaving one primary counter-clockwise circulating vortex. An increase of magnetic field inclination angle leads to modification of convective flow and heat transfer. Even though the isotherms show quasi-conduction domain, the horizontal stratified pattern seem to move upwards near the left wall. This reflects the streamlines formed in the cavity with a significant conduction zone at the bottom wall. When the magnetic field inclination angle increases to $60^{\circ}$, the streamlines show the same patterns as when $\gamma=30^{\circ}$. This can be seen from Figure 9. The primary counterclockwise recirculating vortex occupied the cavity when $H a=30.0$. The circulation seem to skew a little to the left towards the bottom wall when $H a=60.0$. It is worth 
Streamlines
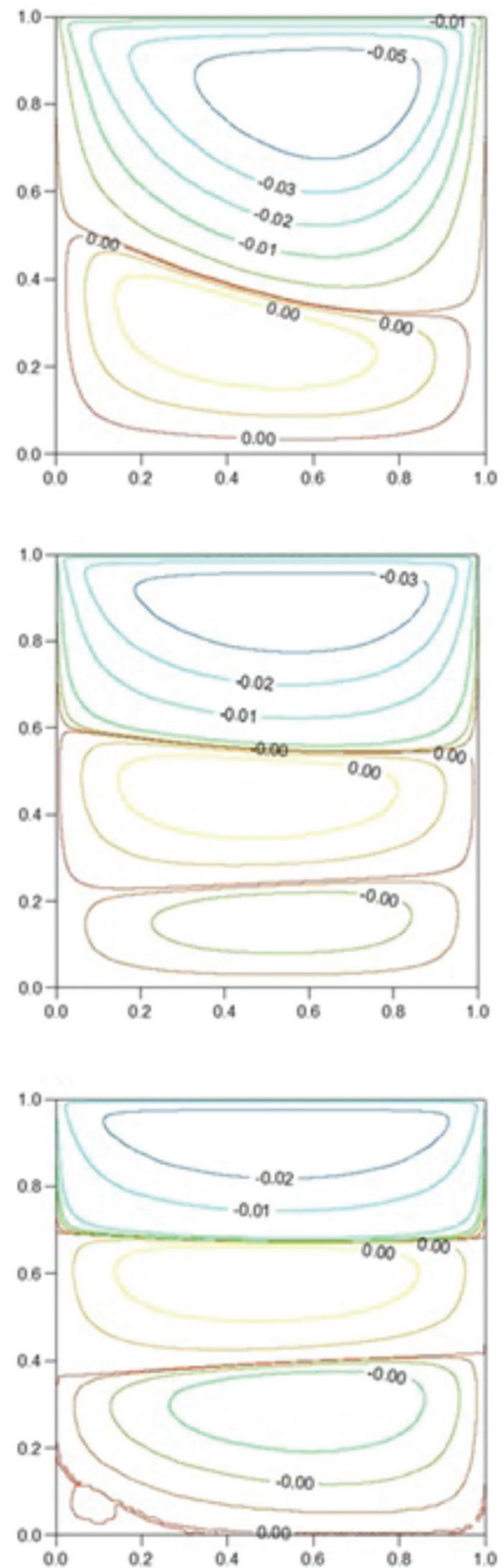

$H a=30.0$

Isotherms
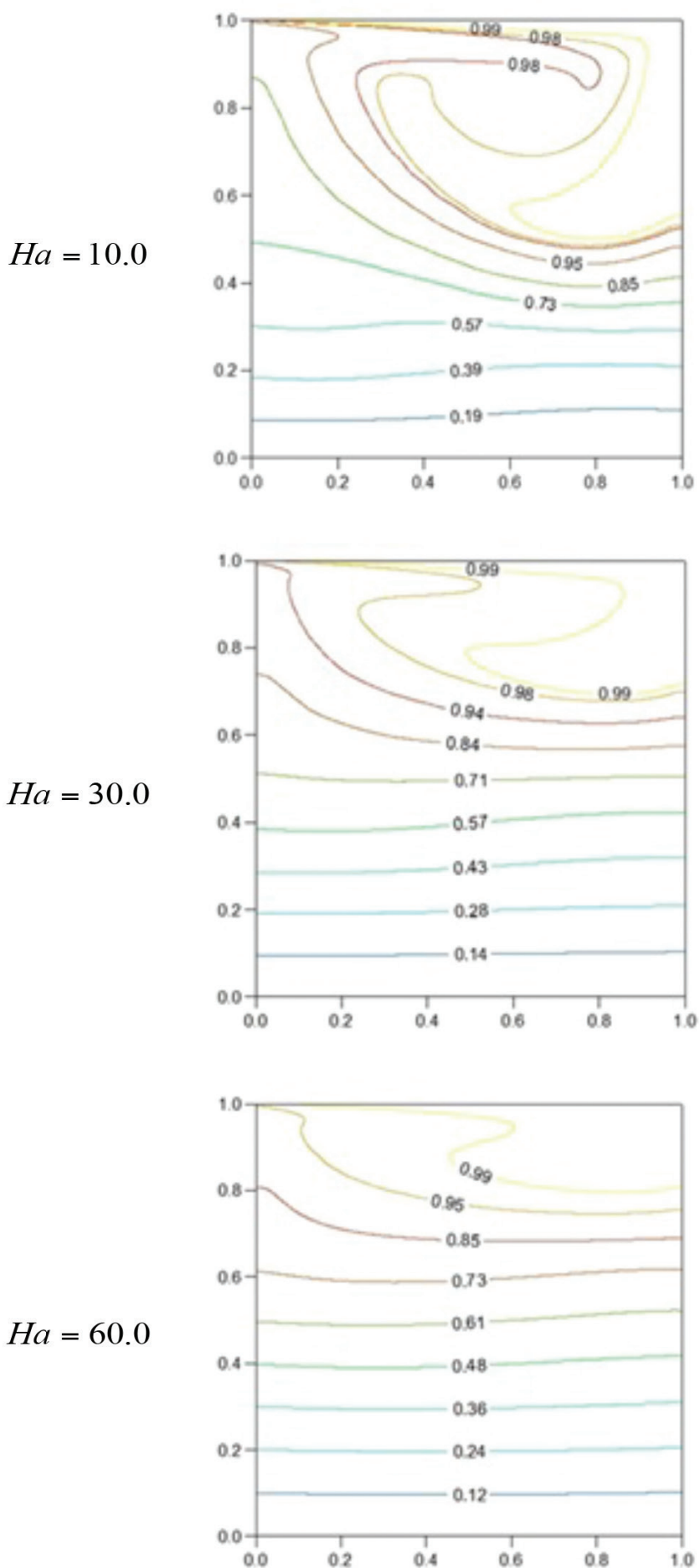

FIGURE 7. Variation of streamlines and isotherms in the cavity with $R i=1.0, R e=100.0$, $G r=10^{4}, \gamma=0$ and different Hartmann number 
Streamlines
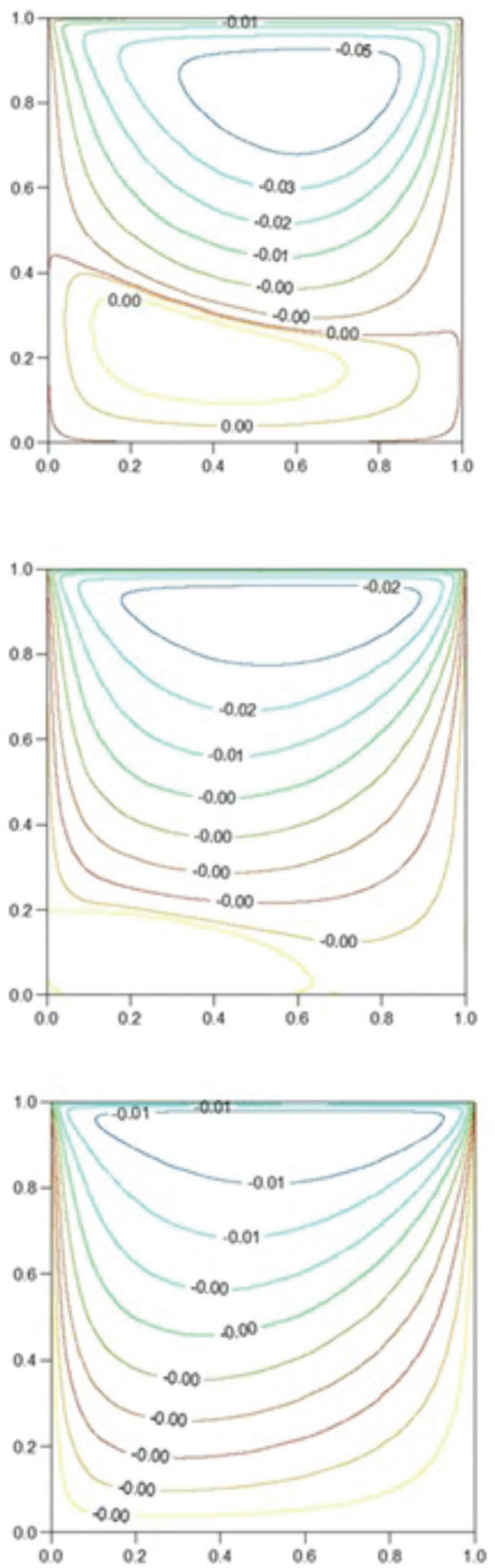

Isotherms

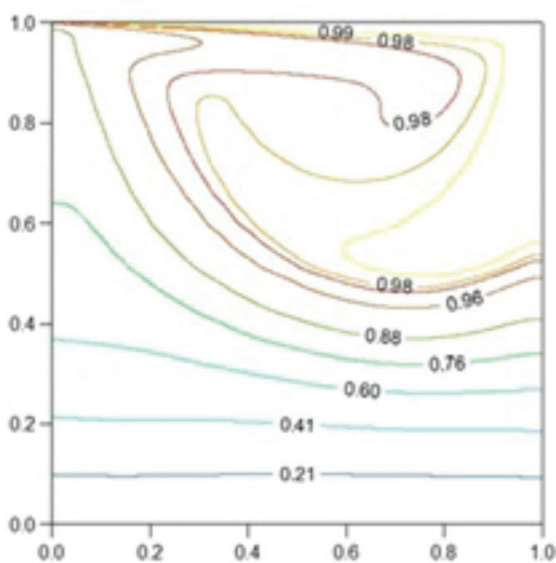

$H a=30.0$

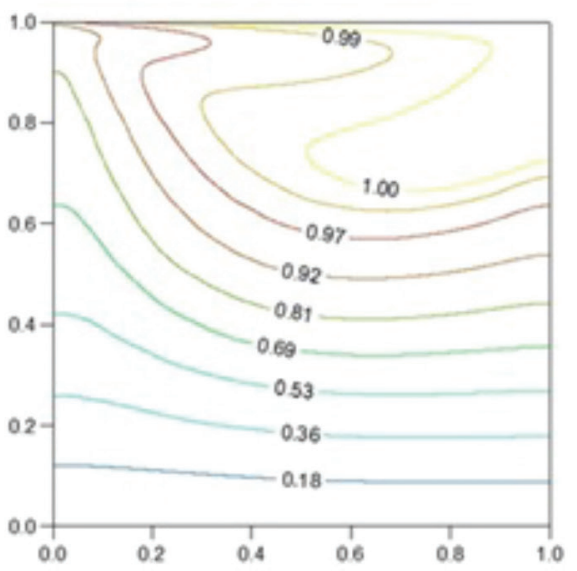

$H a=60.0$

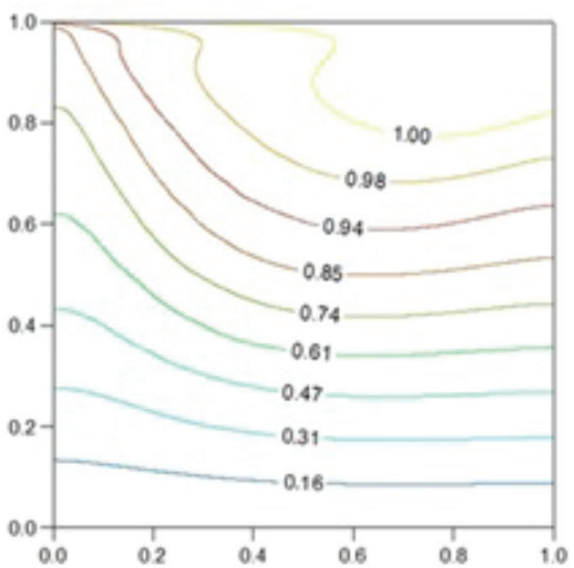

FIGURE 8. Variation of streamlines and isotherms in the cavity with $R i=1.0, R e=100.0$, $G r=10^{4}, \gamma=30^{\circ}$ and different Hartmann number 
Streamlines
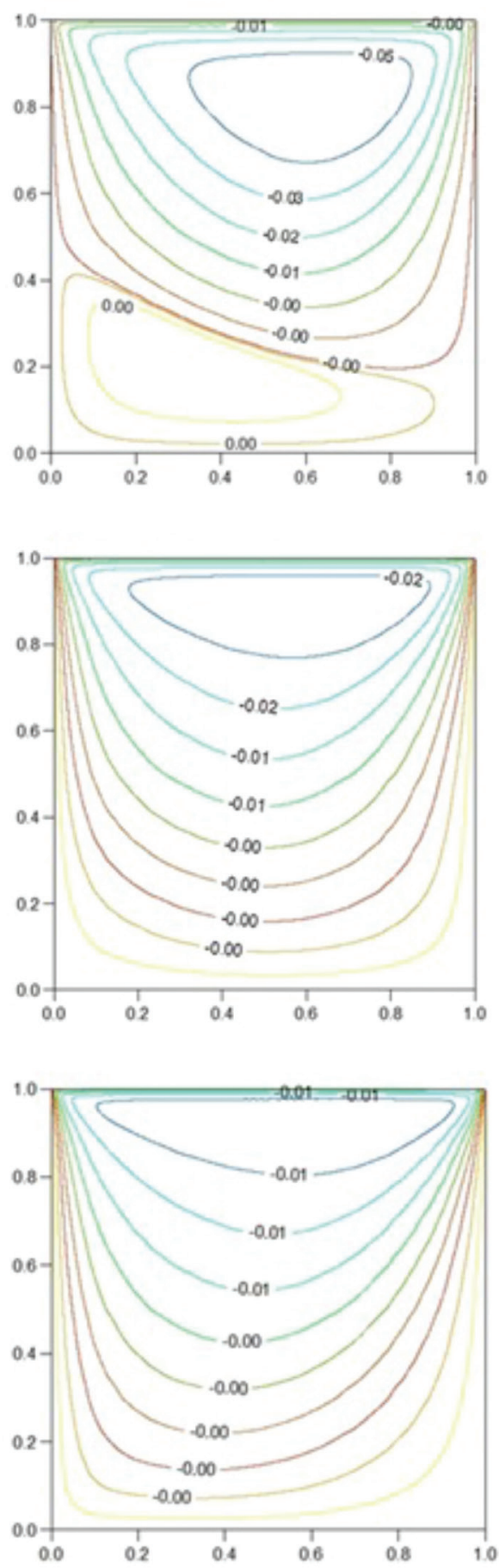

Isotherms

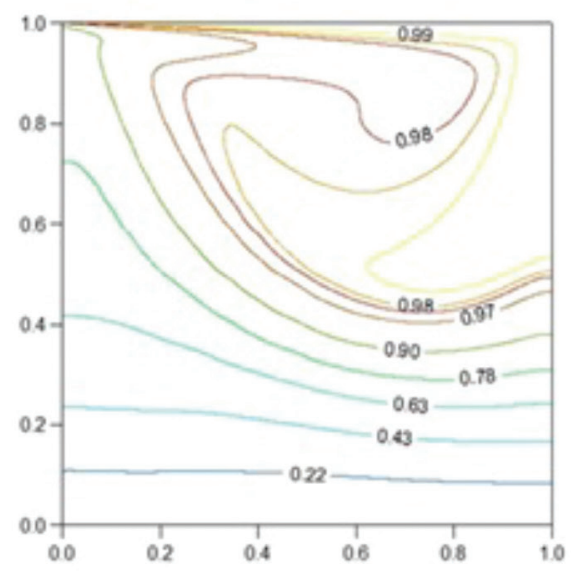

$H a=30.0$

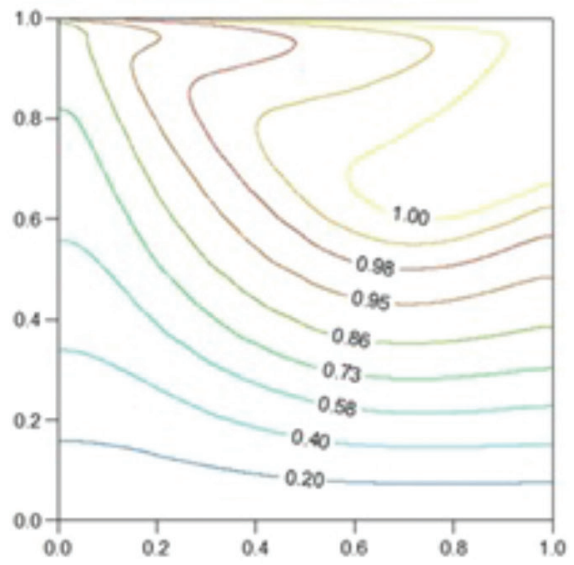

$H a=60.0$

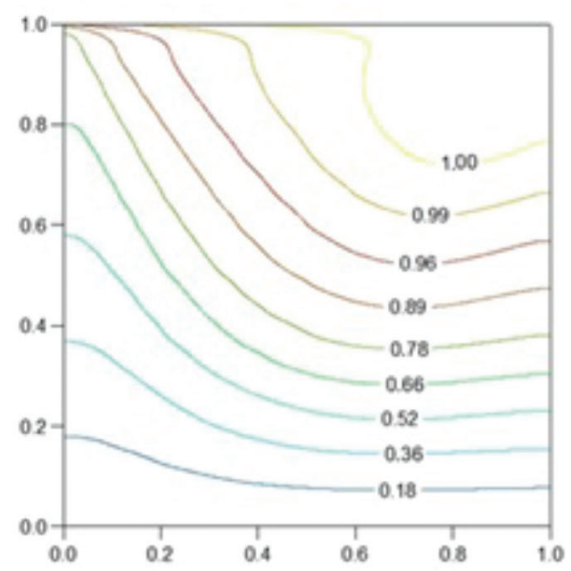

FIGURE 9. Variation of streamlines and isotherms in the cavity with $R i=1.0, R e=100.0$, $G r=10^{4}, \gamma=60^{\circ}$ and different Hartmann number 
mentioning that the skewness of the streamlines close to the left wall is due to the effect of inclined magnetic field imposed. Steep temperature gradient occurs at the middle of the right wall of the cavity. The steep temperature then diminished when $H a=30.0$ and the isotherms is thermally stratified when $H a=60.0$. It can be seen that the isotherms are skewed towards the left wall. From Figure 10, the streamlines and isotherms patterns for $R i=1.0, R e=100.0, G r=10^{4}$ with $\gamma=90^{\circ}$ are the same as when $\gamma=60^{\circ}$. However, the effect of the strength of magnetic field and the inclination angle are significant since the skewness are now close to the right vertical wall due to the difference direction of imposed magnetic field.
Streamlines
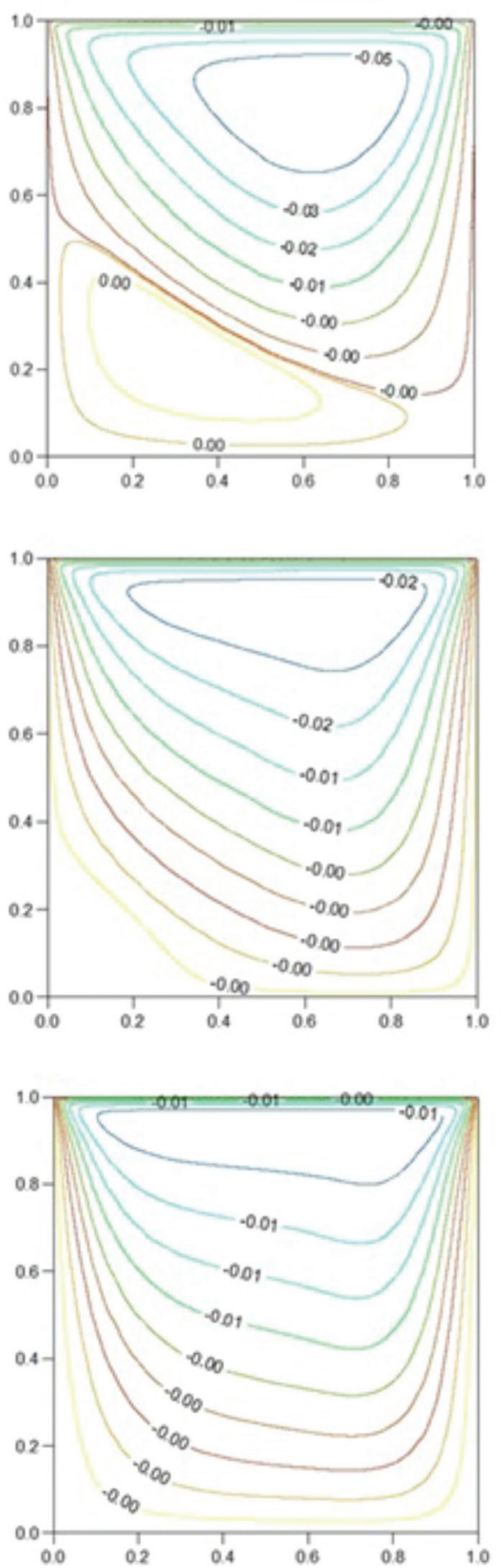

\section{Isotherms}
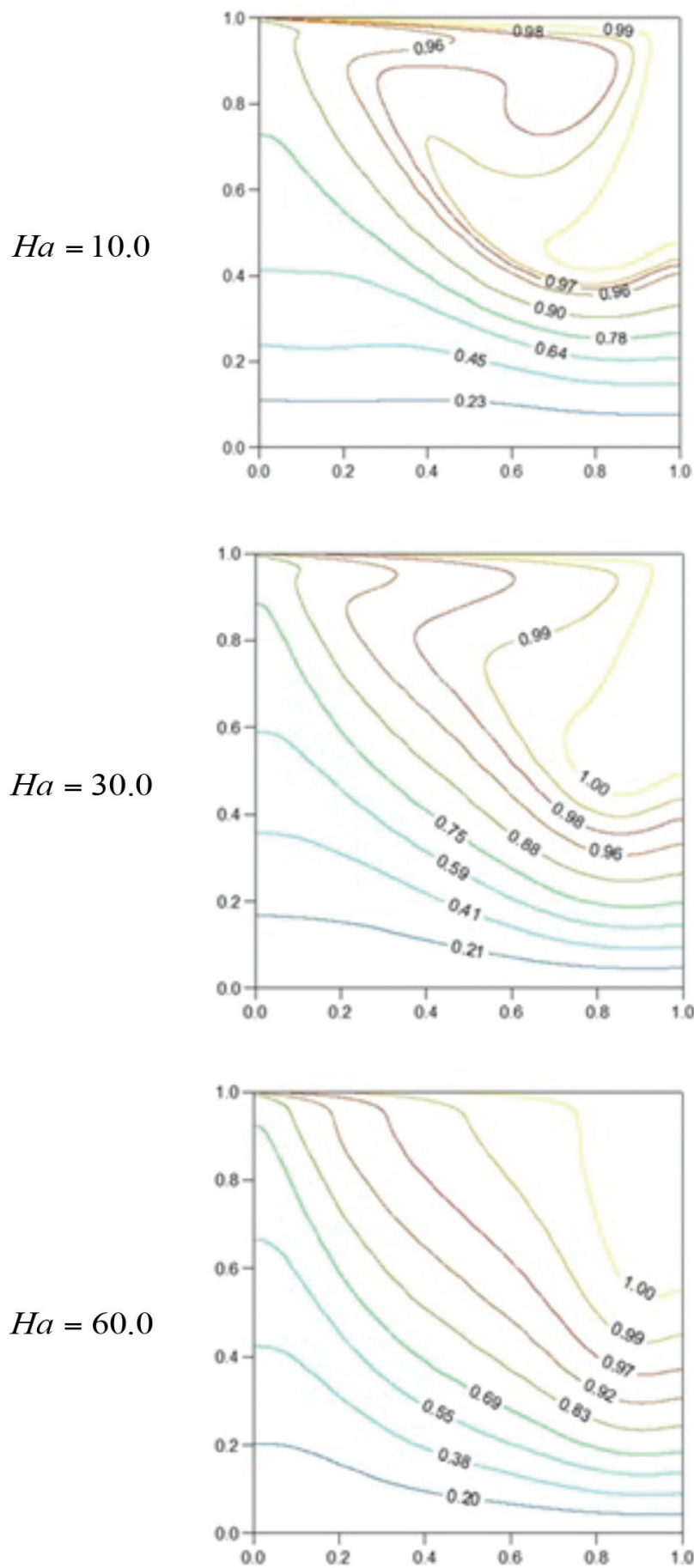

FIGURE 10. Variation of streamlines and isotherms in the cavity with $R i=1.0, R e=100.0$, $G r=10^{4}, \gamma=90^{\circ}$ and different Hartmann number 
Variation of streamlines and isotherms for $R i=10.0$, $R e=100.0, G r=10^{5}$ with various values of $\gamma$ are presented in Figures $11-14$. Figure 11 shows the streamlines and isotherms contour for $\gamma=0^{\circ}$ different strength of magnetic field. The effect of magnetic field strength is more significant than the effect of the lid force. This can be observed by the shrinking and growing eddies at the top and bottom of the cavity, respectively, when the magnetic field strength increases. The isothermal maps are clustered near the right vertical wall resulting a steep temperature gradient there. At the top of the cavity, the temperature differences are small due to the shear driven circulation. In the remaining area, the heat is transferred by conduction. As the magnetic strength increases, the buoyancy force effect are significant especially at the bottom region of the cavity. The effect of cavity inclination angle $\gamma=30^{\circ}$

\section{Streamlines}
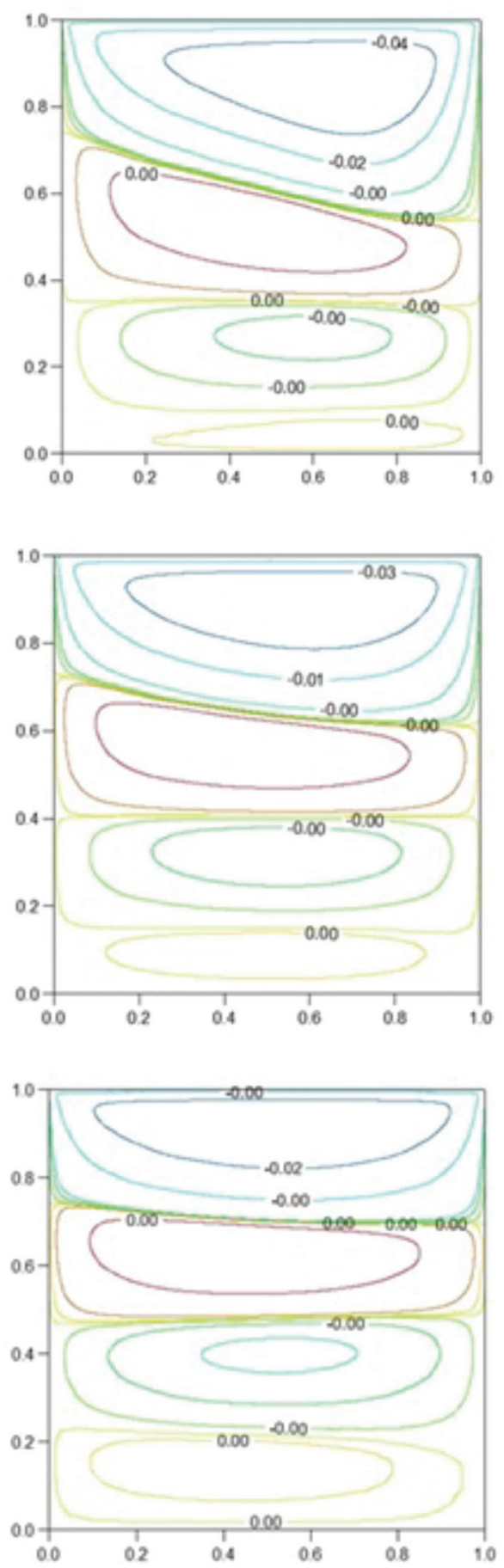

Isotherms

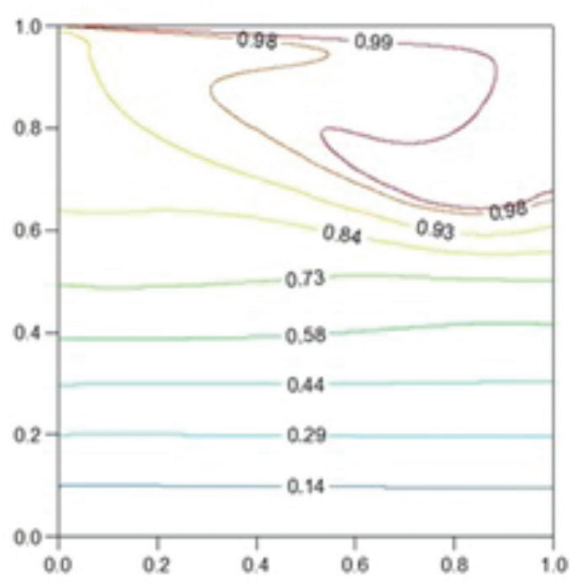

$H a=30.0$
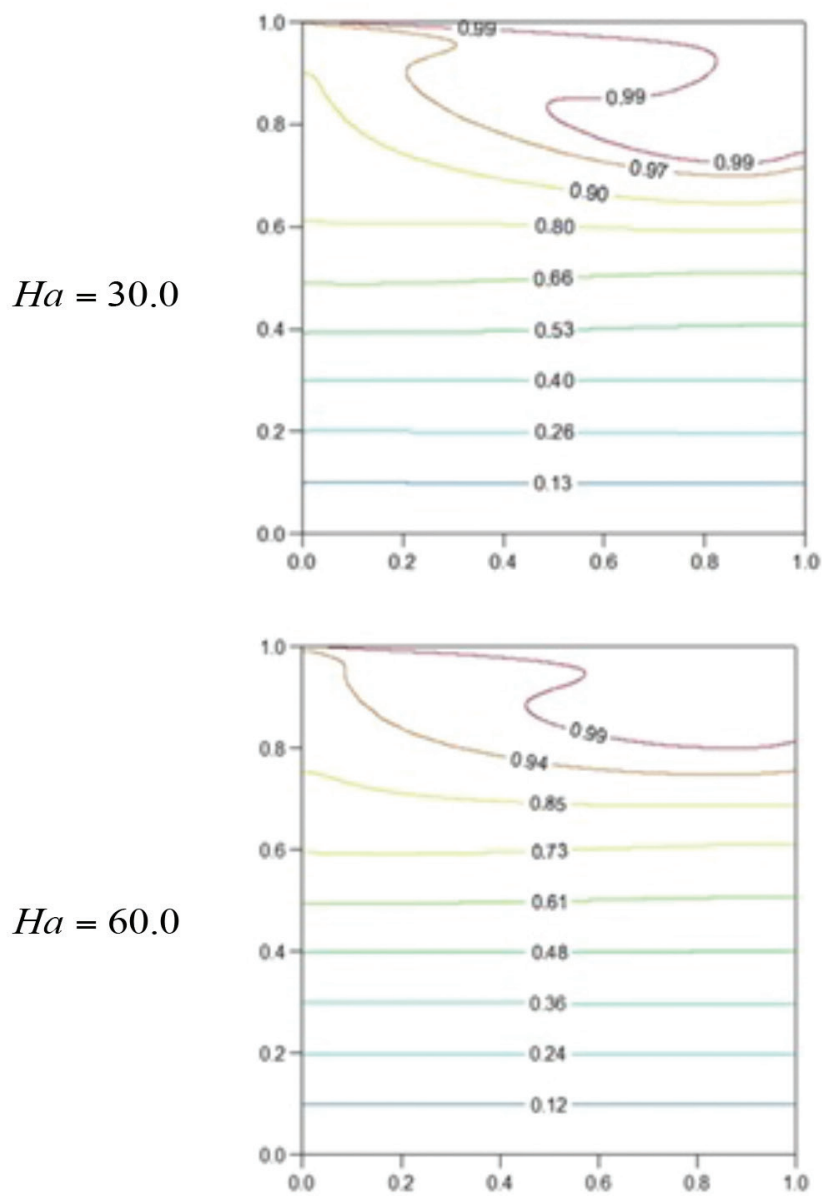

FIGURE 11. Variation of streamlines and isotherms in the cavity with $R i=10.0, R e=100.0$, $G r=10^{5}, \gamma=0^{\circ}$ and different Hartmann number 
for different value of $H a$ at $R i=10.0, R e=100.0, G r=$ $10^{5}$ can be seen from Figure 12. It is observed that at $H a=10.0$, there are three anticlockwise and clockwise vortices formed sequentially. As $\mathrm{Ha}$ increases to 60, the streamlines form two recirculating vortex. The stretching of anticlockwise recirculating vortex at the top of the cavity is increases as the magnetic field strength increase. The isotherms shows quasi-conduction domain where the fluid is horizontally stratified at the bottom of the cavity. As the magnetic field increases, the fluid begin to be thermally stratified in the whole cavity. The isotherms show that starting from the center of the cavity, the fluid is almost vertically stratified. This means that conduction is the main mechanism of heat transfer.

Figure 13 depicted the variations of streamlines and isotherms for different value of $H a$ at $R i=10.0, R e=100.0$,

\section{Streamlines}
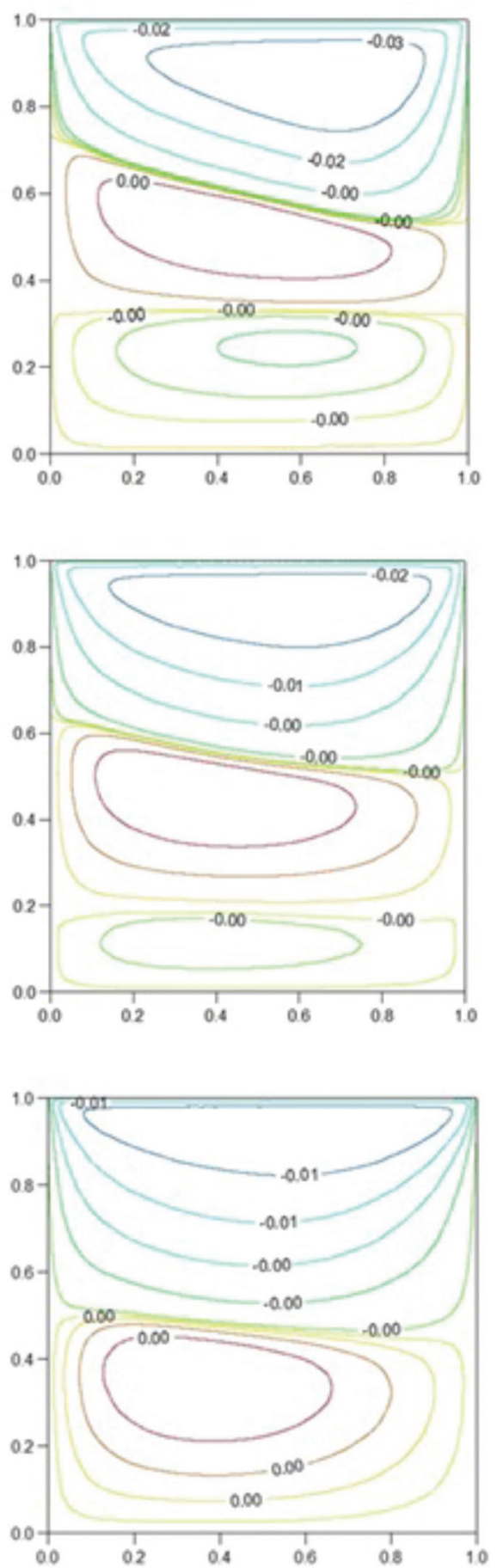

Isotherms

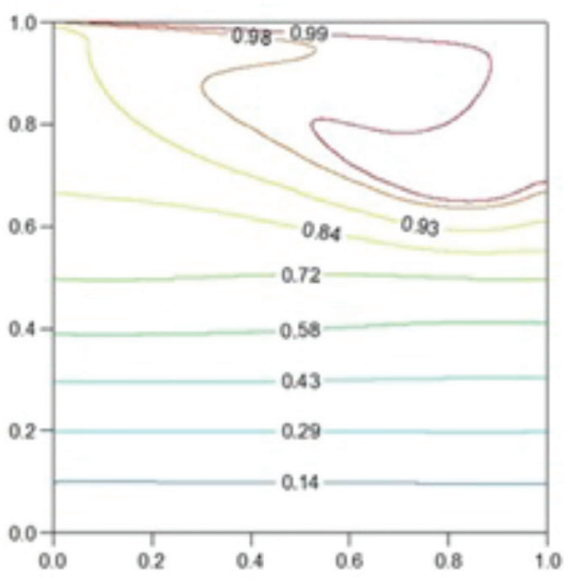

$H a=30.0$

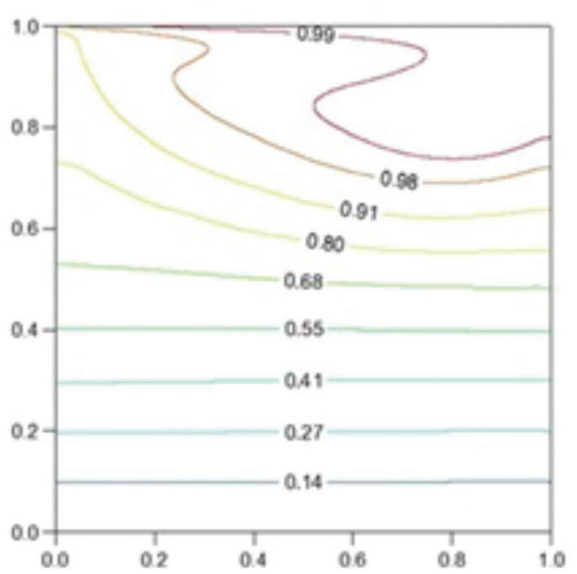

$H a=60.0$

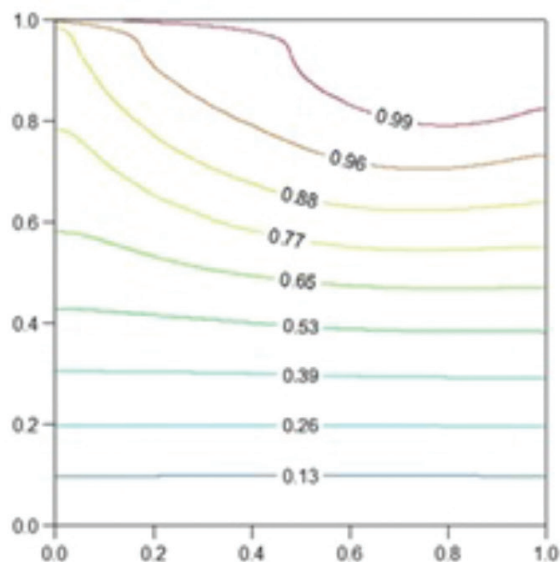

FIGURE 12. Variation of streamlines and isotherms in the cavity with $R i=10.0, R e=100.0$, $G r=10^{5}, \gamma=30^{\circ}$ and different Hartmann number 
$G r=10^{5}$ and $\gamma=60^{\circ}$. The streamlines patterns are of the same pattern in Figure 12. However, when $\mathrm{Ha}=30.0$, only two vortices occupied the cavity compare to Figure 12. When, $H a=60.0$, the anticlockwise vortex is bigger and stoop a little compared to Figure 12 with the same value of magnetic strength. Nevertheless, the isotherms are of the same as in Figure 12. Figure 14 displays the effect of magnetic field inclination angle $\gamma=90^{\circ}$ on the streamlines and isotherms contours for different value of $H a$ at $R i=10.0, R e=100.0, G r=10^{5}$. The contour of both streamlines and isotherms are quite the same patterns as in Figure 13. However, the streamlines are more stretched for all $\mathrm{Ha}$ value than in Figure 13. In addition, the streamlines are more stoop as well. The isotherms patterns are more stoop compare to Figure 13 for all value of $\mathrm{Ha}$. This shows that magnetic field inclination angle plays significant

\section{Streamlines}
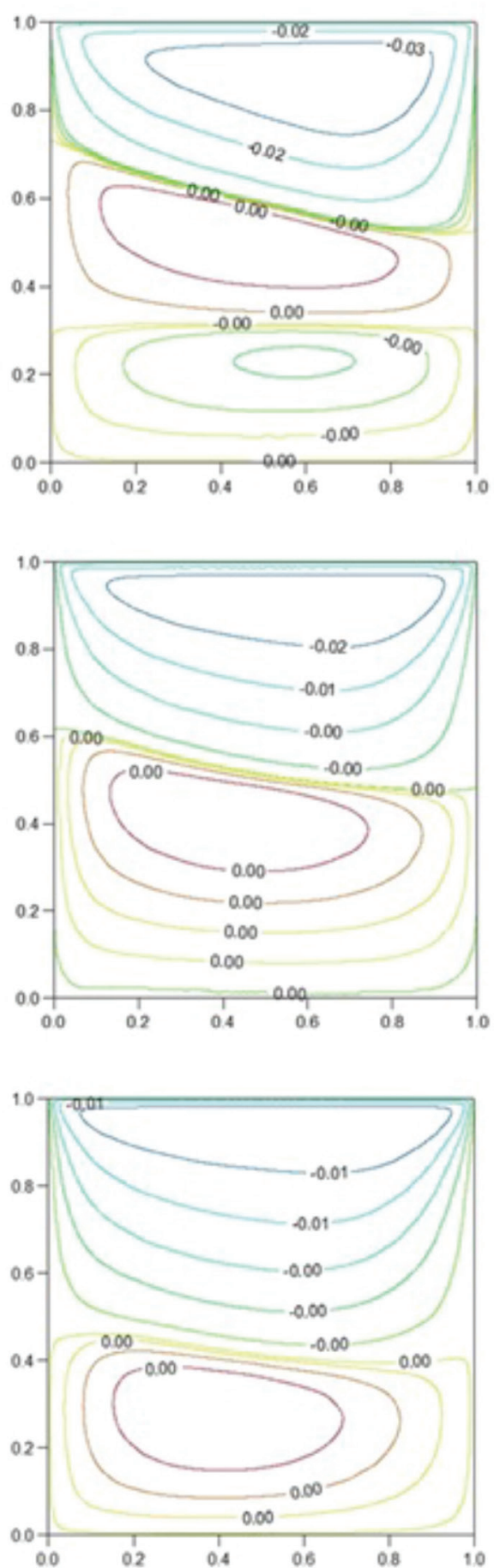

Isotherms

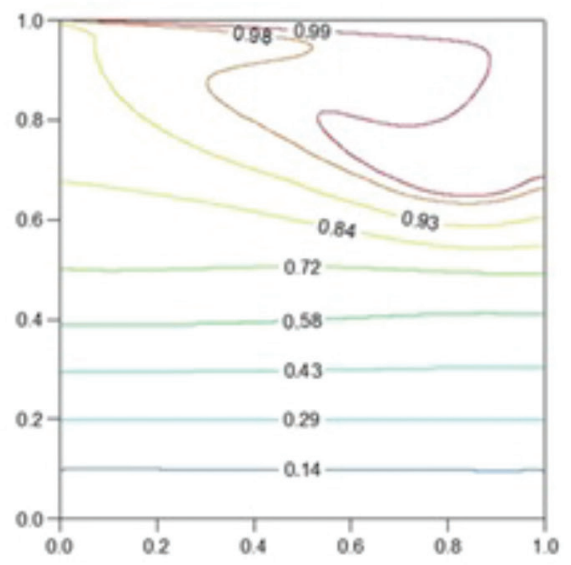

$H a=30.0$

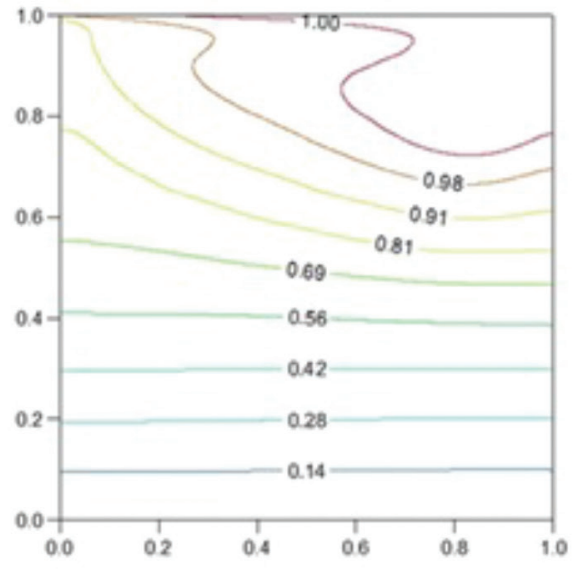

$H a=60.0$

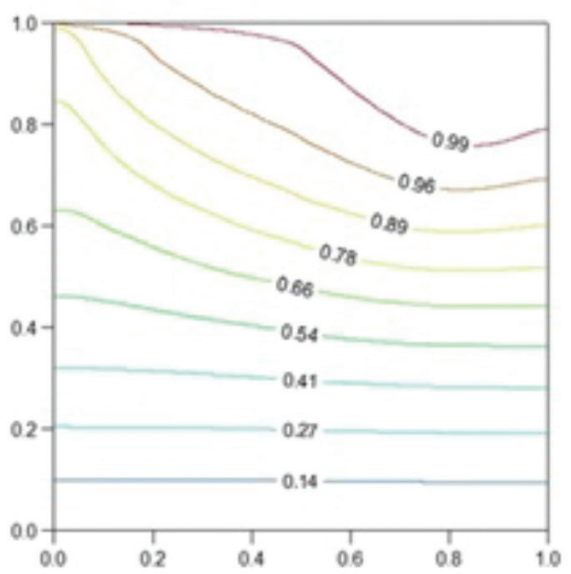

FIGURE 13. Variation of streamlines and isotherms in the cavity with $R i=10.0, R e=100.0$, $G r=10^{5}, \gamma=60^{\circ}$ and different Hartmann number 
Streamlines
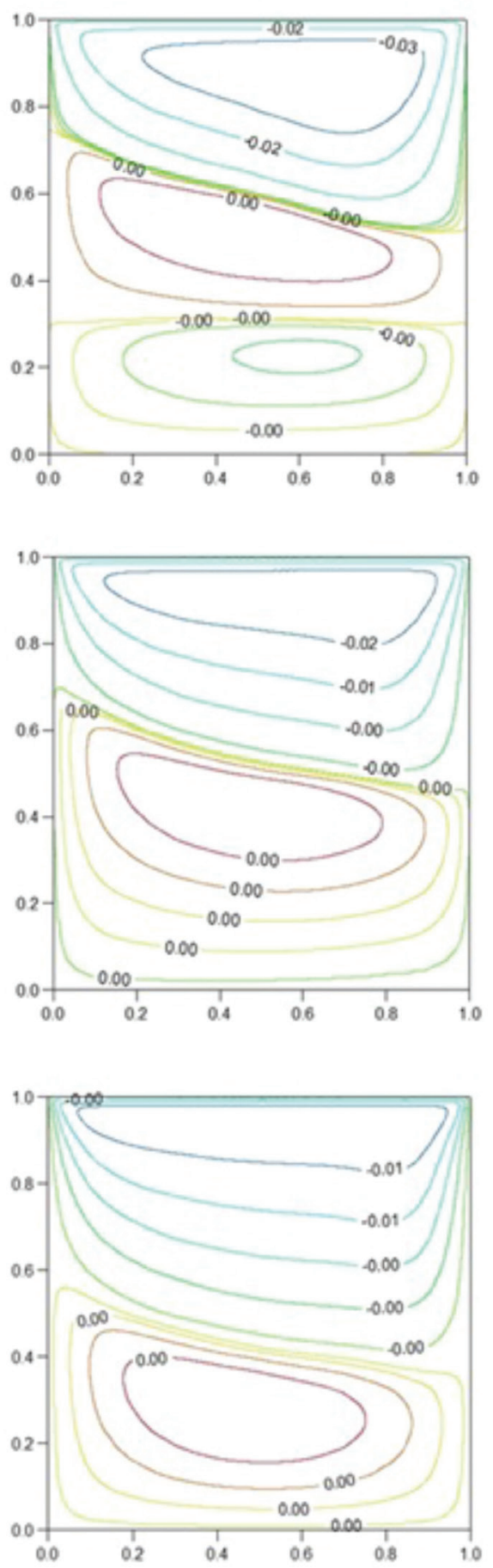

Isotherms

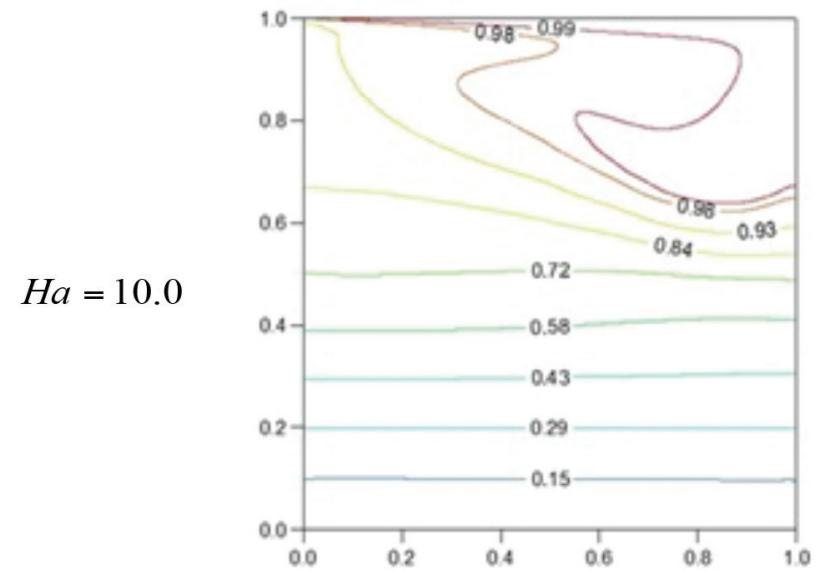

$H a=30.0$

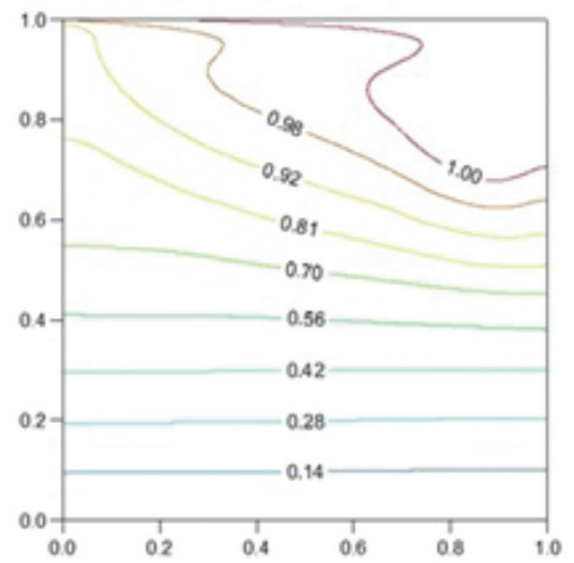

$H a=60.0$

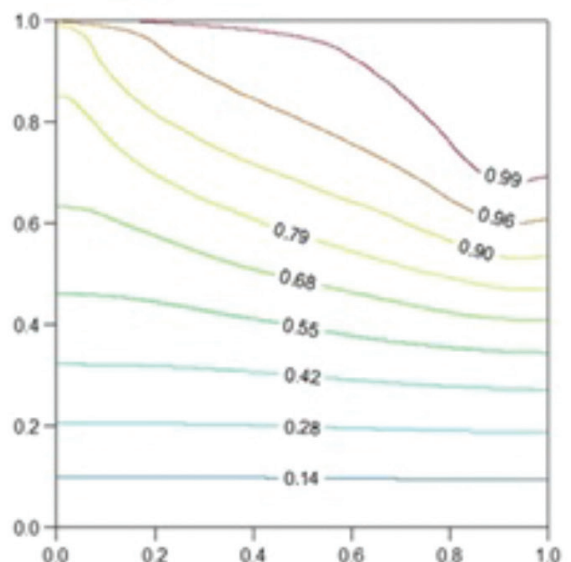

FIGURE 14. Variation of streamlines and isotherms in the cavity with $R i=10.0, R e=100.0$, $G r=10^{5}, \gamma=90^{\circ}$ and different Hartmann number

role in heat transfer and fluid flow for natural convection dominated regime.

The average Nusselt number against different values of $\gamma$ with different values of $R i$ at $H a=30.0$ is shown in Figure 15. It can be seen that there is a decreasing behavior in the heat transfer with an increasing of Richardson number. This phenomenon is due to the movement of the hot top lid. When the comparison of the isotherms of all $R i$ with the same value of $\mathrm{Ha}$, the isothermal lines are denser at the upper part of the cavity and midway of the right wall. This is the result of forced convection forming thinner boundary layers in these regions. Corresponding to that, the steep temperature and concentration gradient causes the increasing in heat and mass transfer rate. As 
the $R i$ increased to 10 , the cavity is in a quasi-conduction domain. This means that most of the heat transfer occurs by conduction especially near the bottom wall. On the other hand, increasing the magnetic inclination angle enhances the heat transfer rate for low $R i$. However, for high $R i$, the heat transfer rate is unaffected by the magnetic inclination angles. Figure 16 displays the effect of magnetic inclination angles on the heat transfer rate with different $\mathrm{Ha}$ values at $R i=1.0$. When there is no magnetic inclination angle, the increase of magnetic field strength will decrease the heat transfer rate. However, as it is evident, increasing the magnetic inclination angle leads to an increase in the heat transfer rate. The average Nusselt number against different value of $H a$ for different value of $R i$ at $\gamma=90^{\circ}$ is shown in Figure 17. Overall, increasing the $\mathrm{Ha}$ result in a reduction of average Nusselt number. This behavior is illustrated in the streamline and isotherms patterns where the magnetic field retarded the heat transfer rate. However, for $R i=1.0$, the heat transfer rate increase a little for $H a=30.0$ and decrease again when $H a=60.0$.

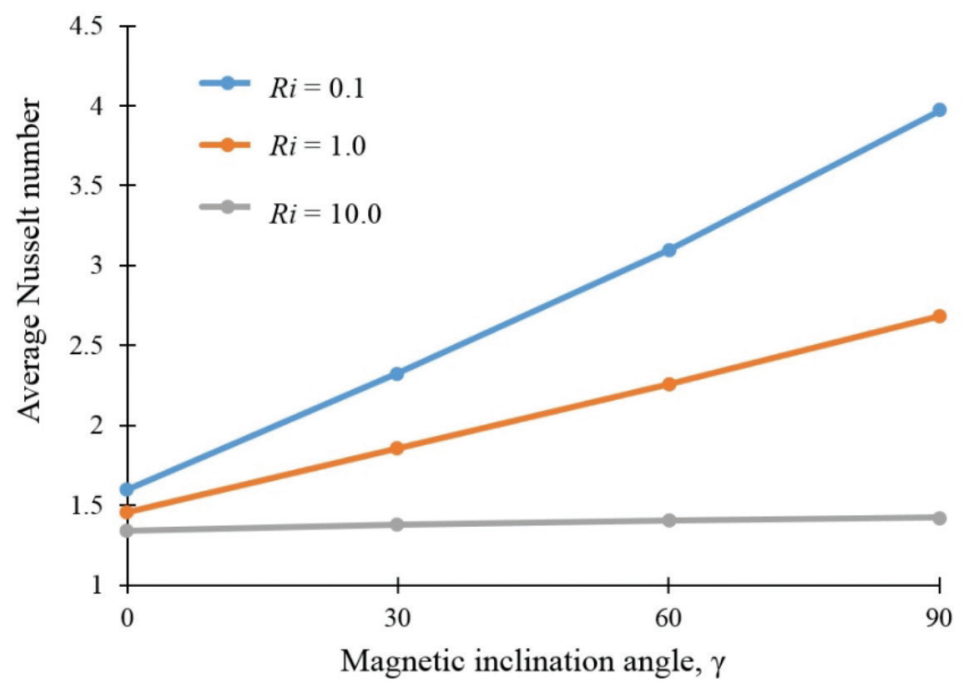

FIGURE 15. Average Nusselt number along the top wall for different value of magnetic inclination angle $\gamma$ with $H a=30.0$

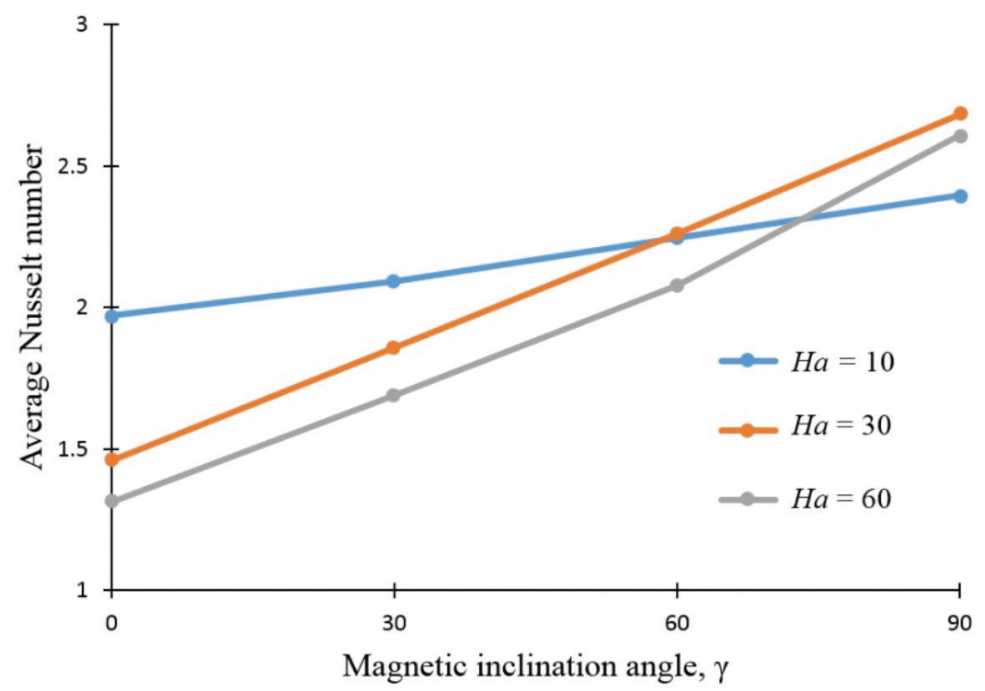

FIGURE 16. Average Nusselt number along the top wall for different value of magnetic inclination angle $\gamma$ with $R i=1.0$ 


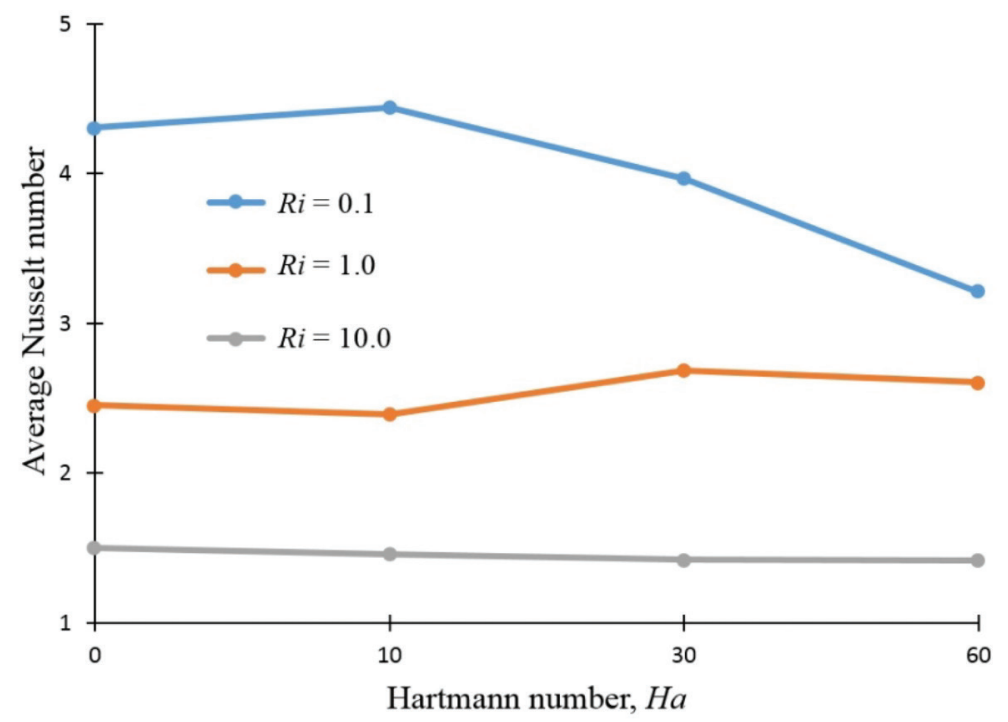

FIGURE 17. Average Nusselt number for different value of $H a$ with magnetic inclination angle $\gamma=90^{\circ}$

\section{CONCLUSION}

The main objective in this study was to investigate the effect of magnetic field inclination angles on the mixed convection in a lid driven square cavity with uniformly heated top wall. The dimensionless governing equations are solved using the finite volume method. From the study, it can be concluded that: heat transfer rate indicated by the average Nusselt number increases by increasing the magnetic field angle, increasing the Richardson number leads to a decrease in the heat transfer rate and mixed convection flow is retarded by the presence of the magnetic field.

\section{ACKNOWLEDGEMENTS}

The author would like to acknowledge the financial support received from Universiti Tun Hussein Onn Malaysia Grant No. TIER 1/H184.

\section{REFERENCES}

Ahmed, S.E., Mansour, M.A. \& Mahdy, A. 2013. MHD mixed convection in an inclined lid-driven cavity with opposing thermal buoyancy force: Effect of non-uniform heating on both side walls. Nuclear Engineering and Design 265: 938-948.

Al-Salem, K., Oztop, H.F., Pop, I. \& Varol, Y. 2012. Effects of moving lid direction in MHD mixed convection in a linearly heated cavity. International Journal of Heat and Mass Transfer 55: 1103-1112.

Bejan, A. 2013. Convection Heat Transfer. Fourth ed., New York: John Wiley \& Sons.

Biswas, N. \& Manna, N.K. 2017a. Enhanced convective heat transfer in lid-driven porous cavity with aspiration. International Journal of Heat and Mass Transfer 114: 430452.

Biswas, N. \& Manna, N.K. 2017b. Transport phenomena in a sidewall-moving bottom-heated cavity using heatlines.
Sadhana-Academy Proceedings in Engineering Sciences 42(2): 193-211.

Biswas, N. \& Manna, N.K. 2017c. Magneto-hydrodynamic Marangoni flow in bottom-heated lid-driven cavity. Journal of Molecular Liquids 251: 249-266.

Biswas, N., Manna, N.K. \& Mahapatra, P.S. 2016. Enhanced thermal energy transport using adiabatic block inside liddriven cavity. International Journal of Heat and Mass Transfer 100: 407-427.

Chamkha, A.J. 2002. Hydromagnetic combined convection flow in a vertical lid-driven cavity with internal heat generation or absorption. Numerical Heat Transfer Part A 41: 529-546.

Garandet, J.P., Alboussiere, T. \& Moreau, R. 1992. Buoyancy driven convection in a rectangular enclosure with a transverse magnetic field. International Journal of Heat and Mass Transfer 35: 741-748.

Gibanov, N.S., Sheremet, M.A., Oztop, H.F. \& Hamdeh, N.A. 2017a. Effect of uniform inclined magnetic field on mixed convection in a lid-driven cavity having a horizontal porous layer saturated with a ferrofluid. International Journal of Heat and Mass Transfer 114: 1086-1097.

Gibanov, N.S., Sheremet, M.A., Oztop, H.F. \& Nusier, O.K. 2017b. Convective heat transfer of ferrofluid in a lid-driven cavity with a heat-conducting solid backward step under the effect of a variable magnetic field. Numerical Heat Transfer A 72: 54-67.

Hussain, S., Ahmed, S.E. \& Saleem, F. 2018a. Impact of periodic magnetic field on entropy generation and mixed convection. Journal of Thermophysics and Heat Transfer 32(4): 9991012.

Hussain, S., Oztop, H.F., Mehmood, K. \& Hamdeh, N.A. 2018 b. Effects of inclined magnetic field on mixed convection in a nanofluid filled double lid-driven cavity with volumetric heat generation or absorption using finite element method. Chinese Journal of Physics 56(2): 484-501.

Hussain, S., Ahmad, S., Mehmood, K. \& Sagheer, M. 2017. Effects of inclination angle on mixed convective nanofluid flow in a double lid-driven cavity with discrete heat sources. International Journal of Heat and Mass Transfer 106: 847 860. 
Hussain, S., Mehmood, K. \& Sagheer, M. 2016. MHD mixed convection and entropy generation of water-alumina nanofluid flow in a double lid driven cavity with discrete heating. Journal of Magnetism and Magnetic Materials 419: 140-155.

Iwatsu, R., Hyun, J.M. \& Kuwahara, K. 1993. Mixed convection in a driven cavity with a stable vertical temperature gradient. International Journal of Heat and Mass Transfer 36: 16011608.

Ishak, A. 2011. MHD boundary layer flow due to an exponentially stretching sheet with radiation effect. Sains Malaysiana 40(4): 391-395.

Kefayati, G.H.R., Gorji-Bandpy, M., Sajjadi, H. \& Ganji, D.D. 2012. Lattice Boltzmann simulation of MHD mixed convection in a lid-driven square cavity with linearly heated wall. Scientia Iranica B 19(4): 1053-1065.

Khanafer, K.M. \& Chamkha, A.J. 1999. Mixed convection flow in a lid-driven enclosure filled with a fluid-saturated porous medium. Heat and Mass Transfer 42: 2465-2481.

Koopaee, M.K. \& Jelodari, I. 2014. Numerical investigation of magnetic field inclination angle on transient natural convection in an enclosure filled with nanofluid. Engineering Computations 31: 1342-1360.

Malleswaran, A., Sivasankaran, S. \& Bhuvaneswari, M. 2013. Effect of heating location and size on MHD mixed convection in a lid-driven cavity. International Journal of Numerical Methods for Heat \& Fluid Flow 23: 867-881.

Mansour, M.A., Chamkha, A.J., Mohamed, R.A., Abd El-Aziz, M.M. \& Ahmed, S.E. 2010. MHD natural convection in an inclined cavity filled with a fluid saturated porous medium with heat source in the solid phase. Nonlinear Analysis: Modelling and Control 15: 55-70.

Mehmood, K., Hussain, S. \& Sagheer, M. 2017. Numerical simulation of MHD mixed convection in alumina-water nanofluid filled square porous cavity using KKL model: Effects of non-linear thermal radiation and inclined magnetic field. Journal of Molecular Liquids 238: 485-498.

Moallemi, M.K. \& Jang, K.S. 1992. Prandtl number effects on laminar mixed convection heat transfer in a lid-driven cavity. International Journal of Heat and Mass Transfer 35: 1881-1892.

Mondal, S. \& Sibanda, P. 2015. Unsteady double diffusive convection in an inclined rectangular lid-driven enclosure with different magnetic field angles and non-uniform boundary conditions. International Journal of Heat and Mass Transfer 90: 900-910.

Mondal, S. \& Sibanda, P. 2018. An unsteady double diffusive natural convection in an inclined rectangular enclosure with different angles of magnetic field. International Journal of Computational Methods 13(4): 1641015.

Naganthran, K., Nazar, R. \& Pop, I. 2018. Effects of thermal radiation on mixed convection flow over a permeable vertical shrinking flat plate in an Oldroyd-B fluid. Sains Malaysiana 47(5): 1069-1076.

Nasrin, R. \& Parvin, S. 2011. Hydromagnetic effect on mixed convection in a lid-driven cavity with sinusoidal corrugated bottom surface. International Communications in Heat and Mass Transfer 38: 781-789.

Oztop,H.F.,Al-Salem, K. \& Pop, I. 2011.MHD mixed convection in a lid-driven cavity with corner heater. International Journal of Heat and Mass Transfer 54: 3494-3504.

Oztop, H.F., Oztop, M. \& Varol, Y. 2009. Numerical simulation of magnetohydrodynamic buoyancy-induced flow in a non- isothermally heated square enclosure. Communications in Nonlinear Science and Numerical Simulation 14: 770-778.

Patankar, S.V. 1980. Numerical Heat Transfer and Fluid Flow. Hemisphere, Washington DC: Taylor \& Francis.

Pirmohammadi, M., Ghasemi, M. \& Sheikhzadeh, G.A. 2009. Effect of a magnetic field on buoyancy-driven convection in differentially heated square cavity. IEEE Transactions on Magnetics 45: 407-411.

Rahman, M.M.,Alim, M.A. \& Sarker, M.M.A. 2010. Numerical study on the conjugate effect of joule heating and magnatohydrodynamics mixed convection in an obstructed lid-driven square cavity. International Communications in Heat and Mass Transfer 37: 524-534.

Rudraiah, N., Barron, R.M., Venkatachalappa, M. \& Subbaraya, C.K. 1995. Effect of magnetic field on free convection in a rectangular enclosure. International Journal of Engineering Science 33: 1075-1084.

Sarris, I.E., Kakarantzas, S.C., Grecos, A.P. \& Vlachos, N.S. 2005. MHD natural convection in a laterally and volumetrically heated square cavity. International Journal of Heat and Mass Transfer 48: 3443-3453.

Selimefendigil,F.\& Chamkha,A.J. 2018. Magnetohydrodynamics mixed convection in a power law nanofluid-filled triangular cavity with an opening using Tiwari and Das nanofluid model. Journal of Thermal Analysis and Calorimetry 2018: 1-18.

Selimefendigil, F. \& Oztop, H.F. 2018. Modeling and optimization of MHD mixed convection in a lid-driven trapezoidal cavity filled with aluminawater nanofluid: Effects of electrical conductivity models. International Journal of Mechanical Sciences 136: 264-278.

Shekholeslami, M.,Ashorynejad, H.R., Domairry, D. \& Hashim, I. 2012. Investigation of the laminar viscous flow in a semi-porous channel in the presence of uniform magnetic field using Optimal Homotopy Asymptotic Method. Sains Malaysiana 41(10): 1281-1285.

Sivasankaran, S., Malleswaran, A., Lee, J. \& Sundar, P. 2011. Hydro-magnetic combined convection in a lid-driven cavity with sinusoidal boundary conditions on both sidewalls. International Journal of Heat and Mass Transfer 54: 512-525.

Torrance, K., Davis, R., Eike, K., Gill, P., Gutman, D., Hsui, A., Lyons, S.\& Zien, H. 1972. Cavity flows driven by buoyancy and shear. Journal of Fluid Mechanics 51: 221-231.

Udhayakumar, S., Rejeesh, A.D.A., Sekhar, T.V.S. \& Sivakumar, R. 2016. Numerical investigation of magnetohydrodynamic mixed convection over an isothermal circular cylinder in presence of an aligned magnetic field. International Journal of Heat and Mass Transfer 95: 379-392.

\section{N.A. Bakar \& R. Roslan}

Center of Research on Computational Mathematics

Faculty of Applied Sciences \& Technology

Universiti Tun Hussein Onn Malaysia

KM1, Jln. Panchor

84600 Muar, Johor Darul Takzim

Malaysia

\section{A. Karimipour}

Department of Mechanical Engineering

Faculty of Engineering

Najafabad Branch, Islamic Azad University

8514143131 Isfahan

Iran 
I. Hashim*

School of Mathematical Sciences

Faculty of Science \& Technology

Universiti Kebangsaan Malaysia

43600 UKM Bangi, Selangor Darul Ehsan

Malaysia
*Corresponding author; email: ishak_h@ukm.edu.my

Received: 31 March 2018

Accepted: 29 October 2018 